\title{
A hybrid model for prediction of ground-borne vibration due to discrete wheel/rail irregularities
}

\author{
Jens C O Nielsen ${ }^{1}$, Geert Lombaert ${ }^{2}$ and Stijn François ${ }^{2}$ \\ ${ }^{1}$ Department of Applied Mechanics / CHARMEC \\ Chalmers University of Technology \\ SE-412 96 Gothenburg, Sweden \\ jens.nielsen@chalmers.se \\ ${ }^{2}$ Department of Civil Engineering \\ KU Leuven \\ Kasteelpark Arenberg 40 \\ B-3001 Leuven, Belgium \\ geert.lombaert@bwk.kuleuven.be, stijn.francois@bwk.kuleuven.be
}

\begin{abstract}
A hybrid model for the prediction of ground-borne vibration due to discrete wheel and rail irregularities, such as wheel flats, dipped welds and insulated rail joints, is presented. The hybrid model combines the simulation of vertical wheel-rail contact force in the time domain, accounting for parametric excitation due to sleeper periodicity and impact excitation induced by loss of wheel-rail contact, and calculation of ground-borne vibration in the frequencywavenumber domain considering a layered soil model. The model is demonstrated by investigating the influence of wheel flat size and vehicle speed on maximum vertical wheel-rail contact force and free field ground vibration. It is shown that magnitudes of impact load and ground vibration are increasing with increasing wheel flat length (and depth), but the influence of vehicle speed is not as evident. Higher vehicle speeds often lead to loss of wheel-rail contact and severe impact loads but the frequency content of such impact loads is shifted to higher frequencies which may be less significant for ground vibration.
\end{abstract}

\section{Introduction}

Railway traffic influences the environment by emissions of air-borne noise, ground-borne vibration and structure-borne noise. Ground and building vibration perceived as mechanical vibration of the human body has a frequency content ranging from $1 \mathrm{~Hz}$ up to around $80 \mathrm{~Hz}$ $[1,2]$. Structure-borne noise, containing frequencies in the interval $16-250 \mathrm{~Hz}$, is generated by vibrations propagating in the ground and radiated as noise from building walls and floors [1]. For an extensive overview on noise and vibration induced by railway traffic, see [2].

Railway vehicle induced ground vibration is generated by both the quasi-static and dynamic components of the set of vertical wheel-rail contact forces between train and track. The quasistatic excitation is determined by the static component of the moving axle loads, axle Postprint submitted to Journal of Sound and Vibration

Published version: J.C.O. Nielsen, S. François, and G. Lombaert,. A hybrid model for prediction of ground-borne vibration due to discrete wheel/rail irregularities. Journal of Sound and Vibration, 345:103-120, 2015. http://dx.doi.org/10.1016/j.jsv.2015.01.021 
distances and vehicle speed, while the dynamic excitation is induced by wheel and rail unevenness (such as wheel polygonalisation and deviations in longitudinal track level), impacts due to discrete wheel and rail irregularities (e.g. wheel flats, rail joints and crossings), and irregularities in track support stiffness (e.g. hanging sleepers, transition zones and culverts). For vehicle speeds well below the wave velocities in the soil, the quasi-static load dominates the track (near field) response whereas the free-field response is dominated by the dynamic loads [1, 3, 4]. Field measurements along conventional lines have shown that the time history of ground vibration velocity during the passage of a freight train has a significantly more irregular character than for passenger and high-speed trains [5]. This indicates that various forms of wheel out-of-roundness (wheel roughness generated by cast iron tread brakes and wheel flats) are more significant in the case of freight traffic.

Most computationally efficient models for the prediction of ground vibration in layered soils are linear and assume continuous wheel-rail contact conditions, see e.g. [6-8]. The vehicle-track-soil interaction is solved in the frequency-wavenumber domain using a socalled 2.5D methodology, where (assuming geometry of track and soil to be uniform in the direction along the track) the problem reduced to 2D is solved for each frequency $\omega$ and wavenumber $k_{y}$ to compute the response in the $x z$-plane. The 3D solution is then obtained by an inverse Fourier transformation with respect to the wavenumber $k_{y}$. Note that these models are not able to account for spatial variation of support stiffness (parametric excitation), because of the assumed regularity of the problem geometry, or non-linear wheel-rail contact phenomena (impact excitation).

To study the influence of parametric and impact excitations, a solution in the time domain is required. Most time domain models for simulation of dynamic vehicle-track interaction account for transient and non-linear wheel-rail contact conditions and do not require the assumption of continuous wheel-rail contact, see e.g. [9, 10]. In general a finite element model approach with rigid boundaries is applied but since a soil (half-space) model is not included such models cannot be used for prediction of ground vibration. In the present study, the benefit of adopting a hybrid approach is that the influence of discrete wheel/rail irregularities on the time history of impact excitation is determined by the time domain model. The Fourier transform of the impact excitation is then used as input to the frequencywavenumber domain model to predict the ground vibration of a layered soil. Similar hybrid approaches for the prediction of noise generated by wheel flats [11] and ground vibration [12] have been presented by other authors. For an accurate combination of the two models, it is required that the vehicle and track receptances at the wheel-rail contacts of the two models are similar. While this generally is not a problem for the vehicle receptance, it may be a challenge for the track receptance due to the significant differences between the two models in the modelling of ballast and ground. In particular, the low frequency track receptance (say below $50 \mathrm{~Hz}$ ) can be difficult to model correctly in the time domain model because the receptance at these frequencies is dominated by the (layered) soil conditions.

Postprint submitted to Journal of Sound and Vibration

Published version: J.C.O. Nielsen, S. François, and G. Lombaert,. A hybrid model for prediction of ground-borne vibration due to discrete wheel/rail irregularities. Journal of Sound and Vibration, 345:103-120, 2015. http://dx.doi.org/10.1016/j.jsv.2015.01.021 
As stated above, the dynamic component of the vertical wheel-rail contact force due to wheel and rail irregularities is an important source to ground vibration and structure-borne noise. The application of mitigation measures at source is an efficient strategy to reduce ground vibration. This means monitoring and early detection of wheel and rail defects and proactive maintenance. The influence of track irregularities and wheel out-of-roundness (OOR) on dynamic wheel-rail excitation was studied in the seventh Framework Programme project RIVAS (Railway Induced Vibration Abatement Solutions) supported by the European Commission, see [13]. The focus of this paper is the investigation of impact excitation due to wheel flats on ground vibration. However, the same approach can be used to study the influence of other types of discrete wheel/rail irregularities.

\section{Wheel out-of-roundness}

A literature review and a classification of wheel out-of-roundness (OOR) are presented in [14]. Out-of-round railway wheels can have a detrimental influence on track and vehicle components, contributing to increased risks of rail breaks, sleeper cracking, high-cycle fatigue of wheels and axles, and bearing damage [14]. Impact noise, rolling noise and ground vibration are other consequences of wheel out-of-roundness. Examples of wheel OOR are local tread damage such as wheel flats causing severe repeated impact loads, and polygonal wheels containing a periodic deviation from the nominal wheel radius that is dominated by a few wavelengths (orders, harmonics) around the wheel circumference. A polygonal wheel leads to increased components of the dynamic vertical wheel-rail contact force at certain excitation frequencies that are determined by vehicle speed and the irregularity wavelengths, whereas wheel flats generate impact forces with significant contributions in a wide frequency range.

There are several mechanisms that may result in out-of-round wheels. Examples are irregular wear around the wheel circumference, brake system failures, wheel machining issues, misaligned axle bore holes, surface or subsurface initiated fatigue cracking, local variations in material microstructure, plastic deformation and build-up of brake block material on the wheel tread [14]. In the present study, the focus is on investigating the influence of discrete wheel tread defects (such as wheel flats) on ground vibration.

\subsection{Discrete wheel tread defect}

A discrete wheel tread defect is a deviation from the nominal wheel radius on a small section of the wheel tread that for each wheel revolution may generate an impact load in the wheel-rail contact. One common discrete tread defect, the wheel flat (see Figure 1), is developed due to unintentional sliding (without rolling) of the wheel along the rail. The reason for the sliding may be that the brakes are poorly adjusted, frozen or defective, or that the braking force is too high in relation to the available wheel-rail friction [15]. As a Postprint submitted to Journal of Sound and Vibration 
consequence, part of the wheel tread is worn off and locally the wheel temperature is raised significantly due to the dissipated friction energy. When the wheel starts rolling again, this is followed by a rapid cooling due to conduction into the large steel volume surrounding the flat. This may lead to material phase transformation (formation of martensite) and residual stresses. The residual stresses are predominantly compressive in the martensitic region and tensile in the region surrounding the martensite [14].

The initial flat with sharp edges will soon be transformed into a longer flat with rounded edges because of wear and plastic deformation of the wheel material due to subsequent impacts with the rail. Furthermore, if martensite is formed, cracks will initiate and propagate in the brittle material caused by the rolling contact loading and the repeated impacts. Due to the tensile residual stresses in the surrounding material, cracks may grow to considerable depths and large parts of the wheel tread may detach.

The maximum allowed length of a discrete wheel tread defect is specified according to EN15313 (standard for wheelset maintenance), see [16]. For a wheel with diameter in the interval $840-1000 \mathrm{~mm}$, axle load 22 tonnes and vehicle speed $100 \mathrm{~km} / \mathrm{h}$, the maximum length is $60 \mathrm{~mm}$ corresponding to a depth in the order of $0.9 \mathrm{~mm}$.

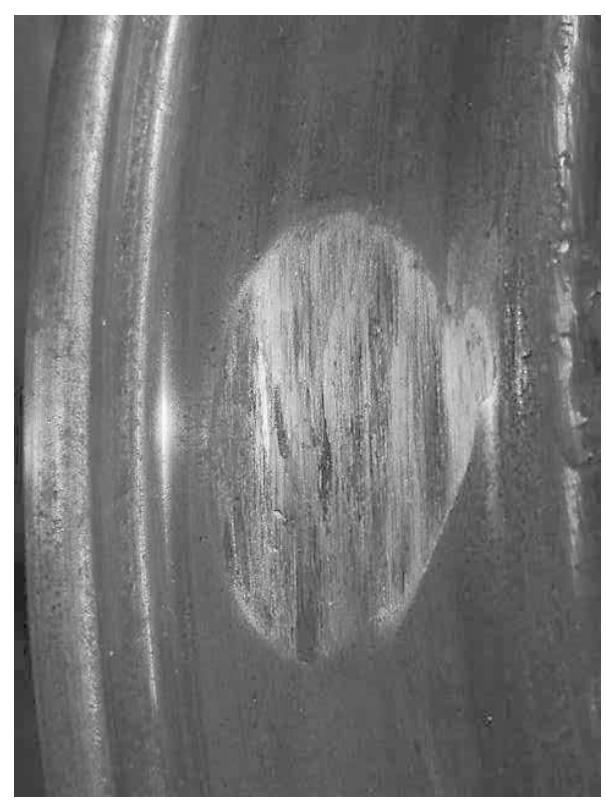

Figure 1. Wheel flat. Photo by Robert Fröhling, Transnet, South Africa

\section{Hybrid model for simulation of ground-borne vibration}

To investigate the influence of discrete wheel/rail irregularities on ground-borne vibration, the features of two different models on dynamic vehicle-track interaction are combined in a hybrid model. Wheel-rail impact load is calculated using a time domain model (DIFF) that Postprint submitted to Journal of Sound and Vibration

Published version: J.C.O. Nielsen, S. François, and G. Lombaert,. A hybrid model for prediction of ground-borne vibration due to discrete wheel/rail irregularities. Journal of Sound and Vibration, 345:103-120, 2015. http://dx.doi.org/10.1016/j.jsv.2015.01.021 
accounts for non-linear wheel-rail contact mechanics as well as parametric excitation due to the spatial variation of support stiffness. The Fourier transform of the impact load is then used as input to a linear model (TRAFFIC) in the frequency-wavenumber domain for the prediction of ground vibration in a layered soil. The present Section provides brief descriptions of the two models for calculation of dynamic vehicle-track-soil interaction and a description of the approach to combine the two.

\subsection{Time domain model for simulation of wheel-rail contact forces}

The DIFF model in Figure 2, which has been developed at Chalmers, is described in detail in [9]. The dynamic vehicle-track interaction is solved in the time domain assuming symmetric track properties with reference to a centre line along the track. Non-linear vehicle, track and wheel-rail contact conditions may be considered, including situations involving loss of (and recovered) wheel-rail contact. Here, the time domain model is used to calculate the transient wheel-rail contact force due to a discrete wheel/rail irregularity.

Since the objective of the demonstration example presented in Section 4 is to investigate the influence of a wheel flat on wheel-rail impact loads and ground-borne vibration, a discretised model of a single wheelset is sufficient. This is because the frequencies excited by the wheel flat are significantly higher than the resonance frequencies in the lower vibration modes of the vehicle. Only a single rail is considered as the loading is assumed to be symmetrically distributed on the two rails. Figure 2(a) illustrates the wheelset model with three degrees-offreedom (dofs) including one massless wheel-rail contact point [11]. The large mass $M_{\mathrm{w}}=$ $712.5 \mathrm{~kg}$ in the wheelset model corresponds to half the wheelset mass of an $\mathrm{SJ} 57 \mathrm{H}$ freight wheelset. The values of the non-physical parameters, the small mass $m_{\mathrm{w}}(3 \mathrm{~kg})$, the spring stiffness $k_{\mathrm{w}}(1650 \mathrm{kN} / \mathrm{mm})$ and the damper $c_{\mathrm{w}}(5.4 \mathrm{kNs} / \mathrm{m})$, have been tuned to better match the vehicle receptance of this model with the corresponding receptance calculated using a detailed FE model of the wheelset, see Figure 2(b). The corresponding receptance of a wheelset model containing only the rigid mass $M_{\mathrm{w}}$ is shown for comparison.

The equations of motion for the wheelset model are written in matrix form (with superscript $\mathrm{w}$ denoting wheelset) as

$$
\begin{aligned}
{\left[\begin{array}{ccc}
0 & 0 & 0 \\
0 & m_{\mathrm{w}} & 0 \\
0 & 0 & M_{\mathrm{w}}
\end{array}\right]\left\{\begin{array}{l}
\ddot{u}_{\mathrm{a}}(t) \\
\ddot{u}_{1}^{\mathrm{v}}(t) \\
\ddot{u}_{2}^{\mathrm{v}}(t)
\end{array}\right\}+\left[\begin{array}{ccc}
0 & 0 & 0 \\
0 & c_{\mathrm{w}} & -c_{\mathrm{w}} \\
0 & -c_{\mathrm{w}} & c_{\mathrm{w}}
\end{array}\right]\left\{\begin{array}{l}
\dot{u}_{\mathrm{a}}(t) \\
\dot{u}_{1}^{\mathrm{v}}(t) \\
\dot{u}_{2}^{\mathrm{v}}(t)
\end{array}\right\}+} \\
{\left[\begin{array}{ccc}
k_{\mathrm{H}} & -k_{\mathrm{H}} & 0 \\
-k_{\mathrm{H}} & k_{\mathrm{H}}+k_{\mathrm{w}} & -k_{\mathrm{w}} \\
0 & -k_{\mathrm{w}} & k_{\mathrm{w}}
\end{array}\right]\left\{\begin{array}{l}
u_{\mathrm{a}}(t) \\
u_{1}^{\mathrm{v}}(t) \\
u_{2}^{\mathrm{v}}(t)
\end{array}\right\}+\left\{\begin{array}{c}
F_{\mathrm{a}}(t) \\
0 \\
0
\end{array}\right\}=\left\{\begin{array}{c}
0 \\
m_{\mathrm{w}} g \\
M_{\mathrm{w}} g
\end{array}\right\} }
\end{aligned}
$$

Postprint submitted to Journal of Sound and Vibration

Published version: J.C.O. Nielsen, S. François, and G. Lombaert,. A hybrid model for prediction of ground-borne vibration due to discrete wheel/rail irregularities. Journal of Sound and Vibration, 345:103-120, 2015. http://dx.doi.org/10.1016/j.jsv.2015.01.021 
Here, $u_{\mathrm{a}}$ is the time-variant downward vertical displacement of the massless contact dof between wheel and rail, $u_{1}^{\mathrm{v}}$ and $u_{2}^{\mathrm{v}}$ are the vertical displacements of the two masses in the wheelset model, $F_{\mathrm{a}}$ is the time-variant wheel-rail contact force and $k_{\mathrm{H}}$ is the non-linear Hertzian wheel-rail contact stiffness (including zero stiffness in tension).

The track model in this study is a finite element model with rigid boundaries at both rail ends and the lower connection point of each spring/damper model representing the soil, see Figure 2(a). The discretely supported rail is modelled by Rayleigh-Timoshenko beam theory. The vertical and rotational stiffness of each rail pad is modelled as a spring and damper coupled in parallel (Kelvin model), and the sleepers are (in this study) taken as discrete masses. The ballast under each sleeper is modelled as a second spring-damper connection with a consistent mass matrix formulation where the ballast mass is distributed on the sleeper and soil masses. The soil under each sleeper is modelled by a rigid mass and by springdamper connections in translation and shear. Each sleeper and each soil mass are constrained to motion in the vertical direction. The influence of variation in sleeper support stiffness along the track may be considered in the model but is not considered here. Input data to the track model is listed in the Appendix.

To reduce the time for simulation of dynamic vehicle-track interaction, the track model is in the present study taken as linear and a modal approach with a truncated modal set is applied. In order to obtain a discrete spectrum of eigenvalues, a finite length of the track is modelled. This means that wave reflections from the track model boundaries will occur and that structure-borne vibrational energy cannot be transmitted away from the structure. The length of the track model needed to limit these effects on calculated responses is dictated by the track and vehicle parameters and by the type of loading studied. In the present study, the track model contains 70 sleeper bays and has clamped ends at both rail boundaries as shown in Figure 2(a).

The $N$ coupled equations of motion of the track model are written in state-space form (with superscript t denoting track) as

$$
\begin{gathered}
\mathbf{A}^{\mathrm{t}} \dot{\mathbf{y}}^{\mathrm{t}}(t)+\mathbf{B}^{\mathrm{t}} \mathbf{y}^{\mathrm{t}}(t)=\left\{\begin{array}{c}
\mathbf{F}^{\mathrm{t}}(t) \\
\mathbf{0}
\end{array}\right\}, \\
\mathbf{y}^{\mathrm{t}}(t)=\left\{\begin{array}{l}
\mathbf{u}^{\mathrm{t}}(t) \\
\dot{\mathbf{u}}^{\mathrm{t}}(t)
\end{array}\right\}, \\
\mathbf{A}^{\mathrm{t}}=\left[\begin{array}{cc}
\mathbf{C}^{\mathrm{t}} & \mathbf{M}^{\mathrm{t}} \\
\mathbf{M}^{\mathrm{t}} & \mathbf{0}
\end{array}\right], \\
\mathbf{B}^{\mathrm{t}}=\left[\begin{array}{cc}
\mathbf{K}^{\mathrm{t}} & \mathbf{0} \\
\mathbf{0} & -\mathbf{M}^{\mathrm{t}}
\end{array}\right]
\end{gathered}
$$

Postprint submitted to Journal of Sound and Vibration

Published version: J.C.O. Nielsen, S. François, and G. Lombaert,. A hybrid model for prediction of ground-borne vibration due to discrete wheel/rail irregularities. Journal of Sound and Vibration, 345:103-120, 2015. http://dx.doi.org/10.1016/j.jsv.2015.01.021 
Here $\mathbf{A}^{\mathrm{t}}$ and $\mathbf{B}^{\mathrm{t}}$ are $2 N \times 2 N$ matrices representing the mass, damping and stiffness of the track model and $N$ is the number of track dofs. The complete modal solution associated with the self-adjoint problem in Equation (2), with a zero right-hand side, is determined from the standard linear algebraic eigenvalue problem

$$
\left[\begin{array}{cc}
\mathbf{K}^{\mathrm{t}^{-1}} \mathbf{C}^{\mathrm{t}} & \mathbf{K}^{\mathrm{t}^{-1}} \mathbf{M}^{\mathrm{t}} \\
-\mathbf{I} & \mathbf{0}
\end{array}\right]\left\{\begin{array}{c}
\underline{\boldsymbol{\rho}}^{(n)} \\
\mathrm{i} \underline{\omega}_{n} \underline{\boldsymbol{\rho}}^{(n)}
\end{array}\right\}=-\frac{1}{\mathrm{i} \underline{\omega}_{n}}\left\{\begin{array}{c}
\underline{\boldsymbol{\rho}}^{(n)} \\
\mathrm{i} \underline{\omega}_{n} \underline{\boldsymbol{\rho}}^{(n)}
\end{array}\right\}
$$

The solution of the eigenvalue problem (3) yields $N$ pairs of complex conjugate sets of eigenvalues $i \underline{\omega}_{n}$ and eigenvectors $\underline{\boldsymbol{\rho}}^{(n)}$ (complex quantities are indicated by an underbar). The eigenvectors are assembled in the modal matrix $\underline{\mathbf{P}}(2 N \times 2 N)$. In the present study, the modal set is truncated to include $M$ conjugate sets of eigenvalues up to eigenfrequency $2200 \mathrm{~Hz}$. The truncated modal matrix $\underline{\mathbf{P}}_{\text {red }}(2 N \times 2 M)$ is written as

$$
\underline{\mathbf{P}}_{\mathrm{red}}=\left[\begin{array}{ccc}
\underline{\boldsymbol{\rho}}^{(1)} & \cdots & \underline{\boldsymbol{\rho}}^{(2 M)} \\
\mathrm{i} \underline{\omega}_{1} \underline{\boldsymbol{\rho}}^{(1)} & \ldots & \mathrm{i} \underline{\omega}_{2 M} \underline{\boldsymbol{\rho}}^{(2 M)}
\end{array}\right]
$$

The equations of motion (2) are transformed into modal space by using the relations

$$
\begin{gathered}
\mathbf{y}^{\mathrm{t}}(t)=\underline{\mathbf{P}}_{\mathrm{red}} \underline{\mathbf{q}}^{\mathrm{t}}(t), \\
\underline{\mathbf{Q}}^{\mathrm{t}}(t)=\underline{\mathbf{P}}_{\mathrm{red}}^{\mathrm{T}}\left\{\begin{array}{c}
\mathbf{F}^{\mathrm{t}}(t) \\
\mathbf{0}
\end{array}\right\}
\end{gathered}
$$

Here $\underline{\mathbf{q}}^{t}(t)$ is the modal displacement vector and $\underline{\mathbf{Q}}^{t}(t)$ is the modal load vector. If non-linear properties of the track model need to be considered, the dynamic vehicle-track interaction is solved directly in the time domain without the modal approach for the track.

Constraint equations, coupling the moving wheels and the stationary rail, are formulated accounting for the influence of the wheel/rail irregularity. Due to the spatial discretisation of the rail model, it is necessary to convert the continuously moving contact force(s) into spatially stationary and consistent time-variant forces located at the nodes of the rail model adjacent to the positions of the real contact force(s). This is achieved by applying the thirddegree interpolation polynomials used as shape functions in the formulation of the beam elements of the finite element model. In the present study, the number of beam elements in one sleeper bay is 16 . At vehicle speed $100 \mathrm{~km} / \mathrm{h}$, the node passing frequency is $740 \mathrm{~Hz}$ which is well above the frequency range of interest here. The complete constraint equations used to couple the wheel-rail contact are given in [9] and will not be repeated here. However, in simplified form the constraint equation can be formulated as

$$
u_{\mathrm{a}}(t)=u_{\mathrm{t}}(y, t)+u_{\mathrm{w} / \mathrm{r}}(y, t)
$$

Postprint submitted to Journal of Sound and Vibration

Published version: J.C.O. Nielsen, S. François, and G. Lombaert,. A hybrid model for prediction of ground-borne vibration due to discrete wheel/rail irregularities. Journal of Sound and Vibration, 345:103-120, 2015. http://dx.doi.org/10.1016/j.jsv.2015.01.021 
where $u_{\mathrm{w} / \mathrm{r}}$ is the prescribed relative wheel-rail displacement due to the discrete wheel/rail irregularity and the length coordinate $y$ is indicating that the wheelset is moving along the track model. The equations of motion for the vehicle and track models and the constraint equation are assembled in matrix form using an extended state-space vector approach, see [9]. By solving an initial value problem for the vehicle-track interaction problem, the time-variant wheel-rail contact force $F_{\mathrm{a}}(\mathrm{t})$ is obtained by time integration and will be used as input to the frequency-wavenumber domain model described in Section 3.2.

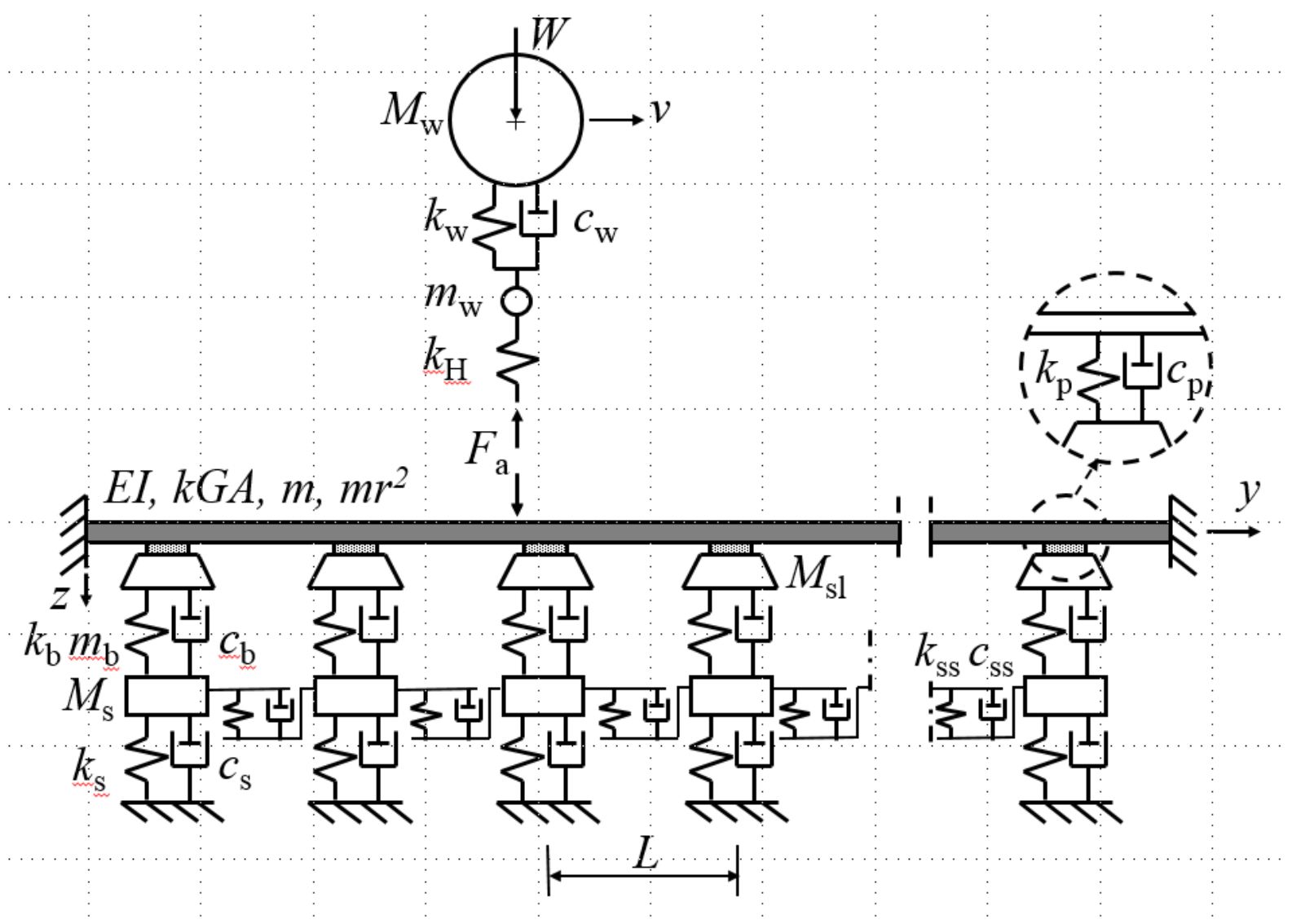

(a) 


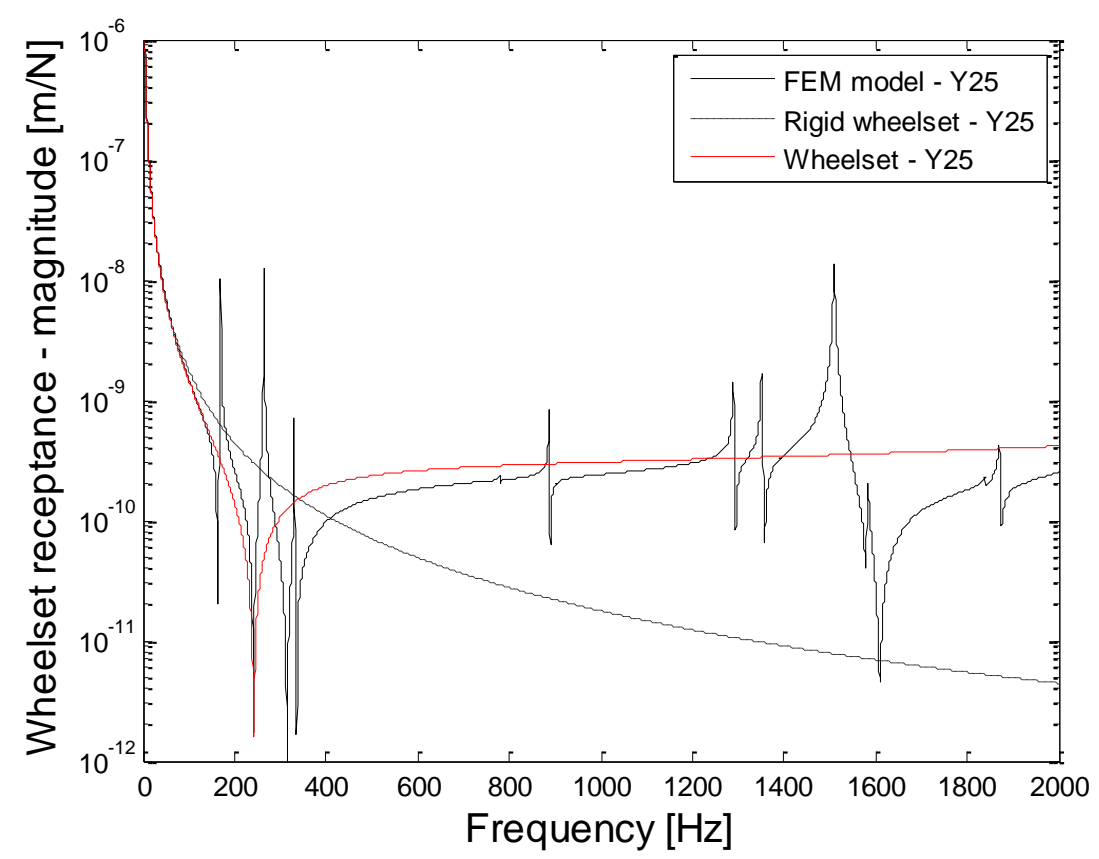

(b)

Figure 2. (a) Vehicle-track interaction model in DIFF, (b) Vehicle model receptance for SJ57H freight wheelset: comparison of results for FEM model and simplified model illustrated in (a)

Postprint submitted to Journal of Sound and Vibration

Published version: J.C.O. Nielsen, S. François, and G. Lombaert,. A hybrid model for prediction of ground-borne vibration due to discrete wheel/rail irregularities. Journal of Sound and Vibration, 345:103-120, 2015. http://dx.doi.org/10.1016/j.jsv.2015.01.021 


\subsection{Frequency-wavenumber domain model for simulation of ground vibration}

A brief recapitulation is made of the TRAFFIC model [8], which has been developed at KU Leuven for the prediction of ground vibration due to road and railway traffic. TRAFFIC is a Matlab toolbox which allows for making predictions of railway induced ground vibration by coupling submodels for train, track and soil. The vehicle model is a relatively simple multibody model, while the models for the track and the soil are coupled finite element - boundary element models which require a much larger modelling and computational effort. The prediction is made in two steps. First, the train-track-soil interaction problem is solved in order to compute the wheel-rail contact forces. Second, these forces are applied to the track and the ground response is computed. Since in the present hybrid approach, the wheel-rail contact forces are computed by the DIFF time domain model, focus here goes to the second step. The reader is referred to the literature [6-8] for more information on the calculation of the wheel-rail contact forces in frequency-wavenumber domain models for railway induced ground vibration.

The coordinate system adopted in TRAFFIC is illustrated in Figure 3(a). Assuming a linear behaviour of the track and the soil, the ground response $u\left(\mathbf{x}^{\prime}, t\right)$ due to a set of $n_{\mathrm{a}}$ wheel-rail contact forces with time history $F_{\mathrm{a} k}(t)$ is computed as follows:

$$
u\left(\mathbf{x}^{\prime}, t\right)=\sum_{k=1}^{n_{\mathrm{a}}} \int_{-\infty}^{t} H_{\mathrm{ts}}\left(\mathbf{x}_{k}(\tau), \mathbf{x}^{\prime}, t-\tau\right) F_{\mathrm{ak}}(\tau) \mathrm{d} \tau
$$

where the transfer function $H_{\mathrm{ts}}\left(\mathbf{x}_{k}(\tau), \mathbf{x}^{\prime}, t-\tau\right)$ (with subscript ts denoting track-soil) relates the response at a point $\mathbf{x}^{\prime}$ to the force at one of the moving contact points $x_{k}(t)$. In the present study, $n_{\mathrm{a}}=1$. When the geometry of the track and the soil are uniform in the direction along the track $\mathbf{e}_{y}$, the motion of the load in Equation (7) can be replaced by an equivalent reverse motion of the receiver:

$$
u\left(\mathbf{x}^{\prime}, t\right)=\sum_{k=1}^{n_{\mathrm{a}}} \int_{-\infty}^{t} H_{\mathrm{ts}}\left(\mathbf{x}_{k 0}, \mathbf{x}^{\prime}-v \tau \mathbf{e}_{y}, t-\tau\right) F_{\mathrm{ak}}(\tau) \mathrm{d} \tau
$$

where $\mathbf{x}_{k}(\tau)$ in Equation (7) has been elaborated as $\mathbf{x}_{k 0}+v \tau \mathbf{e}_{y}$ with $\mathbf{x}_{k 0}$ being the position of the contact point at $t=0$ and $v$ the train speed. In this case, it suffices to compute the transfer function $H_{\mathrm{ts}}\left(\mathbf{x}, \mathbf{x}^{\prime}, t\right)$ for a fixed source position $\mathbf{x}$ and a large number of receivers $\mathbf{x}^{\prime}$ along the track. Omitting the (fixed) source coordinates as arguments of the transfer function, and replacing $\mathbf{x}^{\prime}$ by $\mathbf{x}=\{x, y, z\}^{\mathrm{T}}$ for notational convenience, the latter is rewritten as $H_{\mathrm{ts}}(x, y, z, t)$. Instead of computing the transfer function for a large number of receivers $(x$, $y, z$ ) along the track, it is far more convenient from a computational point of view to compute the transfer function in the frequency-wavenumber domain by applying a Fourier transform with respect to the coordinate $y$ along the track $[17,18]$ :

Postprint submitted to Journal of Sound and Vibration

Published version: J.C.O. Nielsen, S. François, and G. Lombaert,. A hybrid model for prediction of ground-borne vibration due to discrete wheel/rail irregularities. Journal of Sound and Vibration, 345:103-120, 2015. http://dx.doi.org/10.1016/j.jsv.2015.01.021 


$$
\begin{gathered}
\tilde{H}_{\mathrm{ts}}\left(x, k_{y}, z, \omega\right)=\int_{-\infty}^{+\infty} \hat{H}_{\mathrm{ts}}(x, y, z, \omega) \exp \left(\mathrm{i} k_{y} y\right) \mathrm{d} y \\
\hat{H}_{\mathrm{ts}}(x, y, z, \omega)=\frac{1}{2 \pi} \int_{-\infty}^{+\infty} \tilde{H}_{\mathrm{ts}}\left(x, k_{y}, z, \omega\right) \exp \left(-\mathrm{i} k_{y} y\right) \mathrm{d} k_{y}
\end{gathered}
$$

where a hat and a tilde above a variable denote its representation in the frequency domain and frequency-wavenumber domain, respectively.

In this so-called 2.5D methodology, a problem with $2 \mathrm{D}$ geometry is solved for each frequency $\omega$ and wavenumber $k_{\mathrm{y}}$ and the $3 \mathrm{D}$ solution is recovered by an inverse Fourier transformation with respect to the wavenumber $k_{y}$. Because of their high computational efficiency, $2.5 \mathrm{D}$ methods have been applied by a large number of researchers to study dynamic train-track interaction [19] as well as ground-borne vibration due to railway traffic at grade [1, 2, 20-24] and in tunnels [25-27] as an alternative to 3D finite element (FE) methods [28, 29] or 3D coupled finite element - boundary element (BE) methods [30, 31].

A cross section of the $2.5 \mathrm{D}$ ballasted track model assumed in the present study is shown in Figure 3(b). In order to obtain a model with uniform geometry in the direction along the track, the discrete support of the rails by the rail pads and the sleepers is replaced by an equivalent continuous support [8]. The rails are modelled as Euler-Bernoulli beams, continuously supported by spring-dampers representing the rail pads. The sleepers are assumed to be rigid in the plane of the cross section without any stiffness in the longitudinal direction. The ballast bed is assumed to act as a set of distributed non-interacting springs and dampers. The track is located at the surface of a horizontally layered half-space representing the soil. Each layer in the half-space soil model is characterised by its thickness, the longitudinal and transversal wave velocities $C_{\mathrm{p}}$ and $C_{\mathrm{s}}$, material density $\rho$ and material damping ratios $\beta_{\mathrm{p}}$ and $\beta_{\mathrm{s}}$ in volumetric and deviatoric deformation, respectively. The track model is coupled to a boundary element model for the soil. For the computation of the transfer function $\tilde{H}_{\mathrm{ts}}\left(x, k_{y}, z, \omega\right)$, a unit load distributed over both rails is considered.

The response in the free field is computed from the transfer function in the frequencywavenumber domain as follows [7, 8]:

$$
\hat{u}(x, y, z, \omega)=\sum_{k=1}^{n_{\mathrm{a}}} \frac{1}{2 \pi} \int_{-\infty}^{+\infty}\left[\frac{1}{v} \tilde{H}_{\mathrm{ts}}\left(x, \frac{\omega-\tilde{\omega}}{v}, z, \omega\right) \exp \left[-\mathrm{i}\left(\frac{\omega-\tilde{\omega}}{v}\right)\left(y-y_{k 0}\right)\right] \hat{F}_{\mathrm{a} k}(\tilde{\omega}) \mathrm{d} \tilde{\omega}\right.
$$

The transfer function $\tilde{H}_{\mathrm{ts}}\left(x, k_{y}, z, \omega\right)$ is evaluated at a wavenumber $k_{y}=(\omega-\tilde{\omega}) / v$ that couples the frequency $\tilde{\omega}$ emitted by the moving source to the frequency $\omega$ observed at the receiver. This gives rise to the so-called Doppler effect. In the case where the train speed $v$ is relatively low with respect to the wave velocities in the coupled track-soil system, the load motion can be disregarded, leading to the following simplified expression for the free field response:

Postprint submitted to Journal of Sound and Vibration

Published version: J.C.O. Nielsen, S. François, and G. Lombaert,. A hybrid model for prediction of ground-borne vibration due to discrete wheel/rail irregularities. Journal of Sound and Vibration, 345:103-120, 2015. http://dx.doi.org/10.1016/j.jsv.2015.01.021 


$$
\hat{u}(x, y, z, \omega)=\sum_{k=1}^{n_{\mathrm{a}}} \hat{H}_{\mathrm{ts}}\left(x, y-y_{k 0}, z, \omega\right) \hat{F}_{\mathrm{a} k}(\omega)
$$

When excitation due to continuous track unevenness is considered, Equation (11) allows for computing the quasi-stationary part of the response during a train passage. In case of impact loading with a very short duration as considered in the present study, Equation (11) allows for obtaining a good approximation of the entire time history of ground response as the distance travelled by the train in the course of impact is small compared to the overall distance between the source and the receiver. Thus, in the present study, $\hat{F}_{\text {ak }}(\widetilde{\omega})$ (and $n_{\mathrm{a}}=1$ ) is the Fourier transform of the wheel-rail contact force calculated for the single wheelset in the time domain model.

The calculated (TRAFFIC) magnitude of the free field mobility at $8 \mathrm{~m}$ and $16 \mathrm{~m}$ from track is illustrated in Figure 4. At very low frequencies, the attenuation with distance is proportional to $1 / r$. A steep rise as a function of the frequency is found between 10 and $20 \mathrm{~Hz}$. This occurs at the onset of wave propagation in the surface layer, when one quarter of the Rayleigh wavelength computed with the properties of the top soil material fits within the thickness of this layer. A moderate peak is found in the transfer functions near the frequency at which half the Rayleigh wavelength fits within the surface layer [1]. From this frequency on, the surface wave mainly propagates in the soft top layer. The peaks and troughs observed for each of the transfer functions in Figure 4 are due to interference between different types of waves.

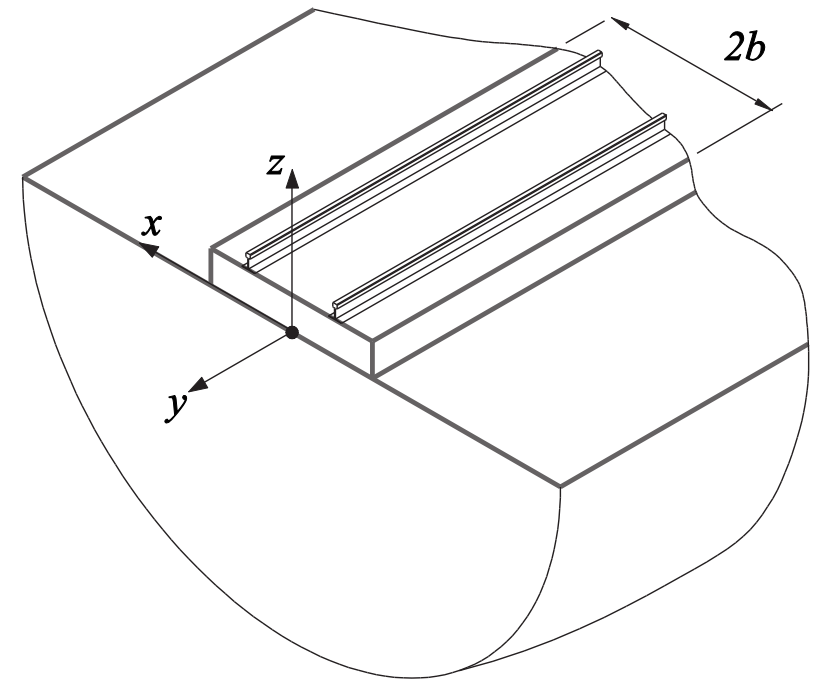

(a)

Postprint submitted to Journal of Sound and Vibration

Published version: J.C.O. Nielsen, S. François, and G. Lombaert,. A hybrid model for prediction of ground-borne vibration due to discrete wheel/rail irregularities. Journal of Sound and Vibration, 345:103-120, 2015. http://dx.doi.org/10.1016/j.jsv.2015.01.021 


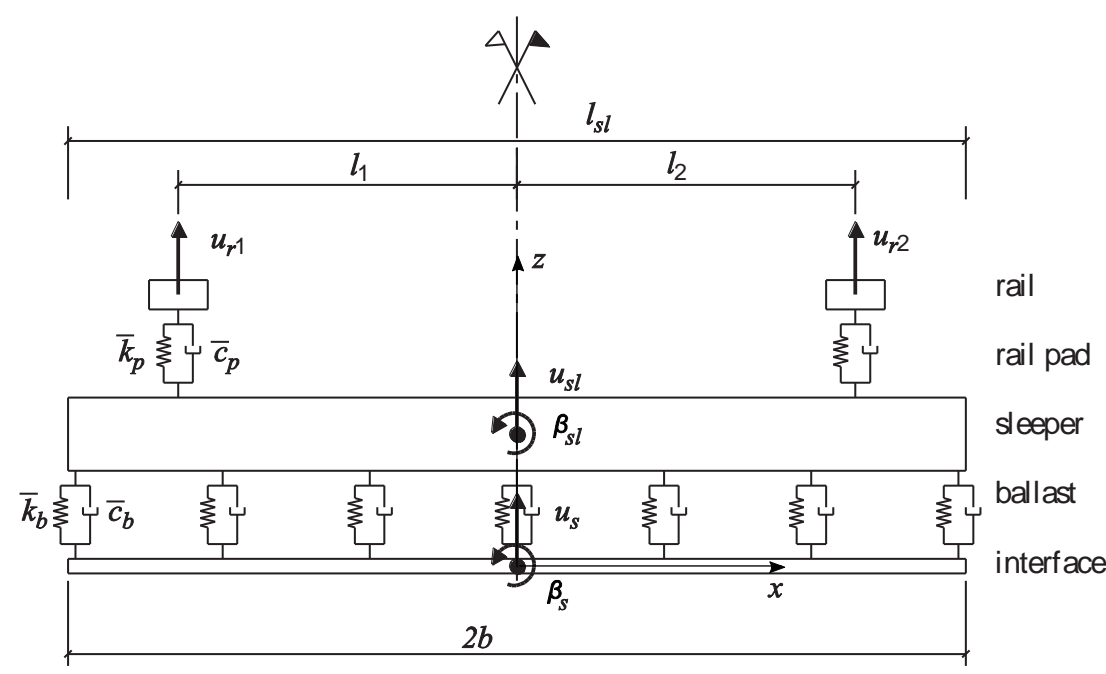

(b)

Figure 3. (a) Coordinate system adopted in TRAFFIC (note opposite directions of vertical axis in DIFF and TRAFFIC), (b) cross-section of ballasted track model in TRAFFIC

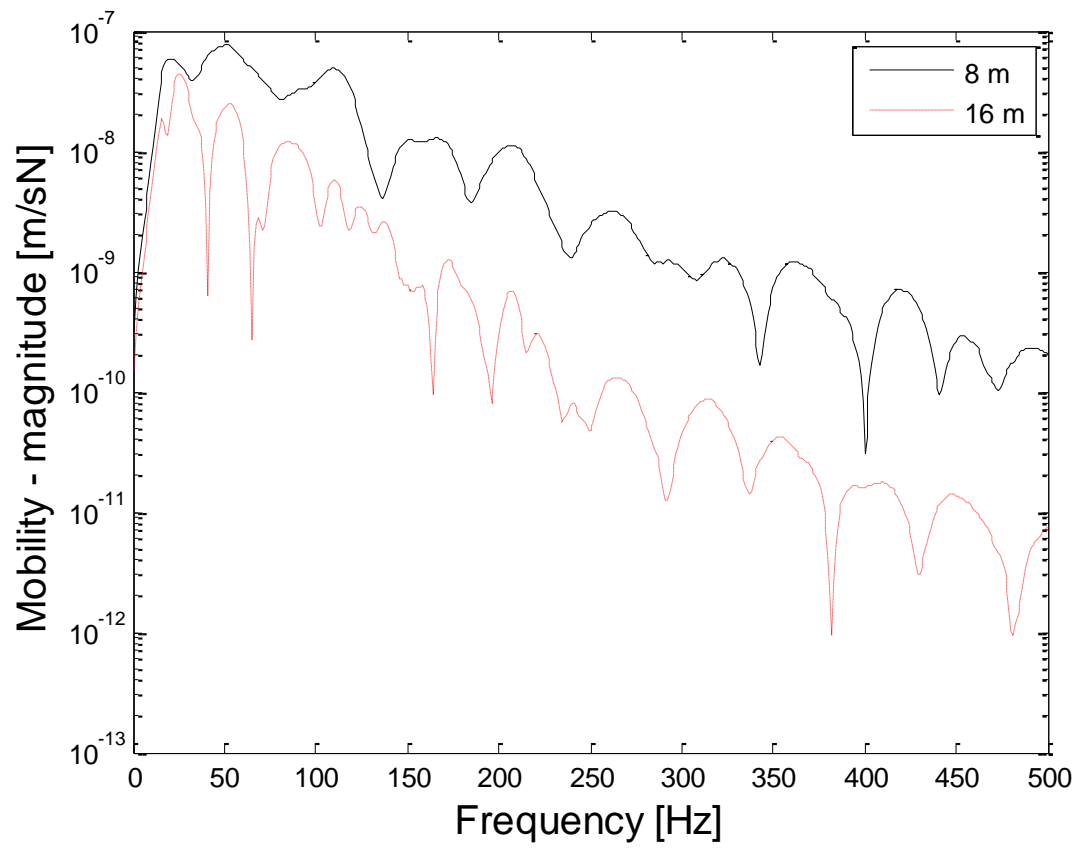

Figure 4. Calculated (TRAFFIC) magnitude of free field mobility (symmetric load applied on two rails) for the Lincent site

\subsection{Tuning of soil parameters in time-domain model}

The soil model in DIFF is a simplified five-parameter representation containing a soil mass and two sets of one spring and one viscous damper coupled in parallel, see Figure 2(a). One of Postprint submitted to Journal of Sound and Vibration

Published version: J.C.O. Nielsen, S. François, and G. Lombaert,. A hybrid model for prediction of ground-borne vibration due to discrete wheel/rail irregularities. Journal of Sound and Vibration, 345:103-120, 2015. http://dx.doi.org/10.1016/j.jsv.2015.01.021 
the spring-damper connections accounts for the vertical stiffness and damping of the soil, whereas the other set of spring and damper provides a shear connection between two adjacent soil masses. The input data for the soil model $\left(M_{\mathrm{s}}, k_{\mathrm{s}}, c_{\mathrm{s}}, k_{\mathrm{ss}}\right.$ and $\left.c_{\mathrm{ss}}\right)$ are unknown and need to be determined by a procedure where the numerical values of the input data are tuned to minimise the error between the track receptances calculated in DIFF and TRAFFIC.

A procedure that can be applied to determine the properties of the soil model in DIFF is described in [32]. Based on the input data for the RIVAS reference track and a set of layered soil model input data corresponding to the RIVAS reference test site Lincent in Belgium, see Appendix, the 'true' track receptance is calculated using the TRAFFIC model. The track receptance (displacement over force) is determined by applying a symmetric vertical load on the two rails of the model and calculating the corresponding symmetric rail displacement. The input parameters for the DIFF soil model are then tuned using a genetic algorithm where the objective function $\Phi$ to be minimised is defined as a quadratic error function based on the sum of differences $\mathbf{e}$ between the receptances calculated in TRAFFIC and DIFF. Only the magnitudes of the receptances are considered in the present minimisation. Although the procedure applied here can easily be extended to account for the errors in both magnitude and phase, see [32], it was found that considering only the error in magnitude resulted in the best agreement between the two models. Since the influence of the soil model on the track receptance is significant only at low frequencies, the receptance of the DIFF model is tuned to the receptance of the TRAFFIC model in the frequency range up to $100 \mathrm{~Hz}$.

The discretised receptance vectors $\hat{\mathbf{H}}^{\mathrm{t}}$ are written as

$$
\hat{\mathbf{H}}^{\mathrm{t}, \text { TRAFFIC }}(\omega)=\left[\begin{array}{c}
\hat{H}^{\mathrm{t}, \mathrm{TRAFFIC}}\left(\omega_{1}\right) \\
\hat{H}^{\mathrm{t}, \mathrm{TRAFFIC}}\left(\omega_{2}\right) \\
\vdots \\
\hat{H}^{\mathrm{t}, \mathrm{TRAFFIC}}\left(\omega_{n}\right)
\end{array}\right], \hat{\mathbf{H}}^{\mathrm{t} \text {,DIFF }}=\left[\begin{array}{c}
\hat{H}^{\mathrm{t}, \text { DIFF }}\left(\omega_{1}\right) \\
\hat{H}^{\mathrm{t}, \text { DIFF }}\left(\omega_{2}\right) \\
\vdots \\
\hat{H}^{\mathrm{t}, \text { DIFF }}\left(\omega_{n}\right)
\end{array}\right]
$$

The error vector $\mathbf{e}$ between the two models is defined as

$$
\mathbf{e}=\log _{10}\left(\hat{\mathbf{H}}^{\mathrm{t}, \mathrm{TRAFFIC}}\right)-\log _{10}\left(\hat{\mathbf{H}}^{\mathrm{t}, \mathrm{DIFF}}\right)
$$

The use of logarithmic values in the error function is motivated by the large variation in receptance in the studied frequency range. Using the MATLAB function ga (genetic algorithm), the objective function

$$
\Phi=\mathbf{e}^{\mathrm{T}} \mathbf{Q e}
$$

is minimised where $\mathbf{Q}$ is a non-negative weighting matrix (diagonal). To improve accuracy of important features of the track receptance, the elements of $\mathbf{Q}$ corresponding to frequencies at resonances and antiresonances of the receptance calculated in TRAFFIC may be assigned higher weights. In load cases where the influence of multiple wheels needs to be accounted for in the model, the accuracy of cross-receptances between adjacent wheel-rail contact positions needs to be verified. This can be accounted for in the tuning procedure by adding the Postprint submitted to Journal of Sound and Vibration

Published version: J.C.O. Nielsen, S. François, and G. Lombaert,. A hybrid model for prediction of ground-borne vibration due to discrete wheel/rail irregularities. Journal of Sound and Vibration, 345:103-120, 2015. http://dx.doi.org/10.1016/j.jsv.2015.01.021 
error between cross-receptances in the objective function and minimizing a weighted sum of the errors in the match in receptance and cross-receptance, in a similar way as attributing weight to frequencies of specific interest.

The result after tuning of the five soil parameters in DIFF for the RIVAS reference site Lincent is illustrated in Figure 5. Good agreement between the two models is observed. Although only the magnitudes of the receptances were used in the minimisation, also the phases of the receptances from the two models are in reasonably good agreement. To assign higher weights to the static receptance and to the receptance at the fundamental resonance of the track model, the weighting matrix $\mathbf{Q}$ was set to 3 for the diagonal elements corresponding

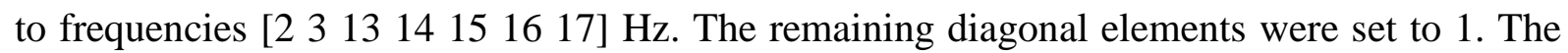
tuned input data for the Lincent soil model in DIFF, see Figure 2(a), are: $M_{\mathrm{s}}=210 \mathrm{~kg}, k_{\mathrm{s}}=$ $11 \mathrm{kN} / \mathrm{mm}, c_{\mathrm{s}}=52 \mathrm{kNs} / \mathrm{m}, k_{\mathrm{ss}}=402 \mathrm{kN} / \mathrm{mm}$ and $c_{\mathrm{ss}}=107 \mathrm{kNs} / \mathrm{m}$. Note that the physical meaning of the tuned input data for the soil model in DIFF is not important as long as the track receptance at the wheel-rail contact is in good agreement with the TRAFFIC model to allow for an accurate calculation of the vertical wheel-rail contact force.

Postprint submitted to Journal of Sound and Vibration

Published version: J.C.O. Nielsen, S. François, and G. Lombaert,. A hybrid model for prediction of ground-borne vibration due to discrete wheel/rail irregularities. Journal of Sound and Vibration, 345:103-120, 2015. http://dx.doi.org/10.1016/j.jsv.2015.01.021 


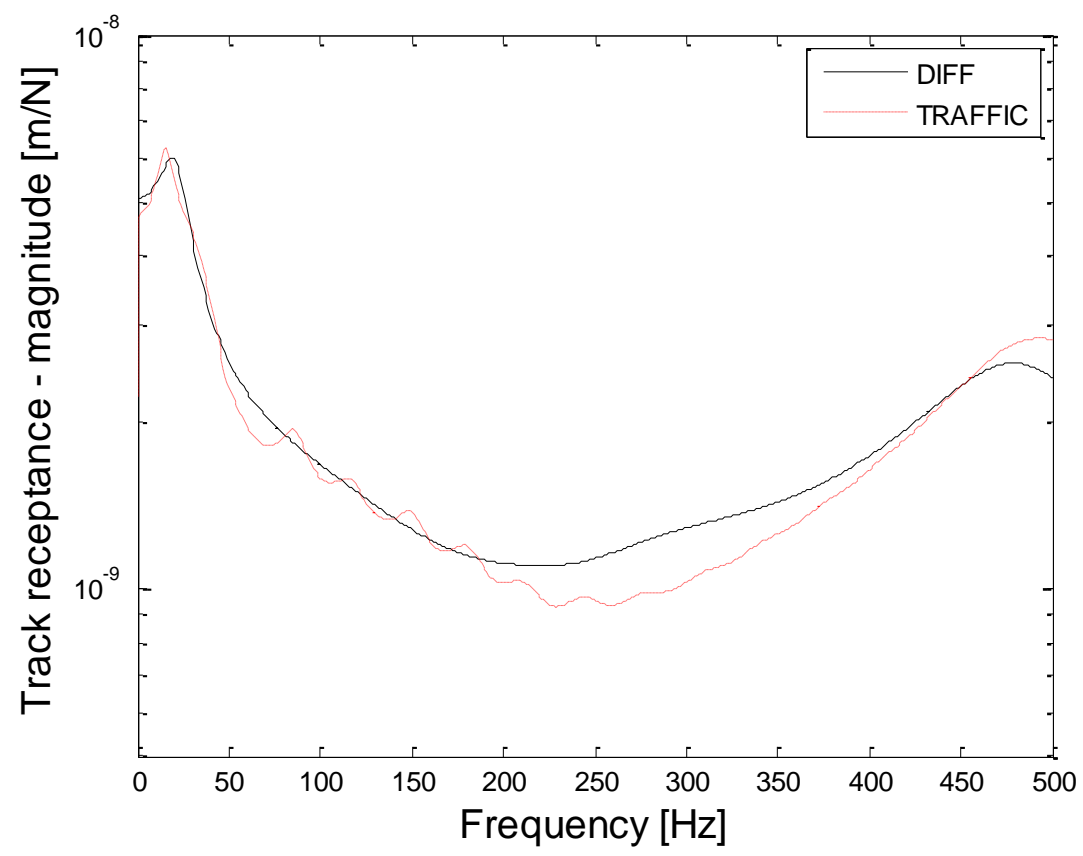

(a)

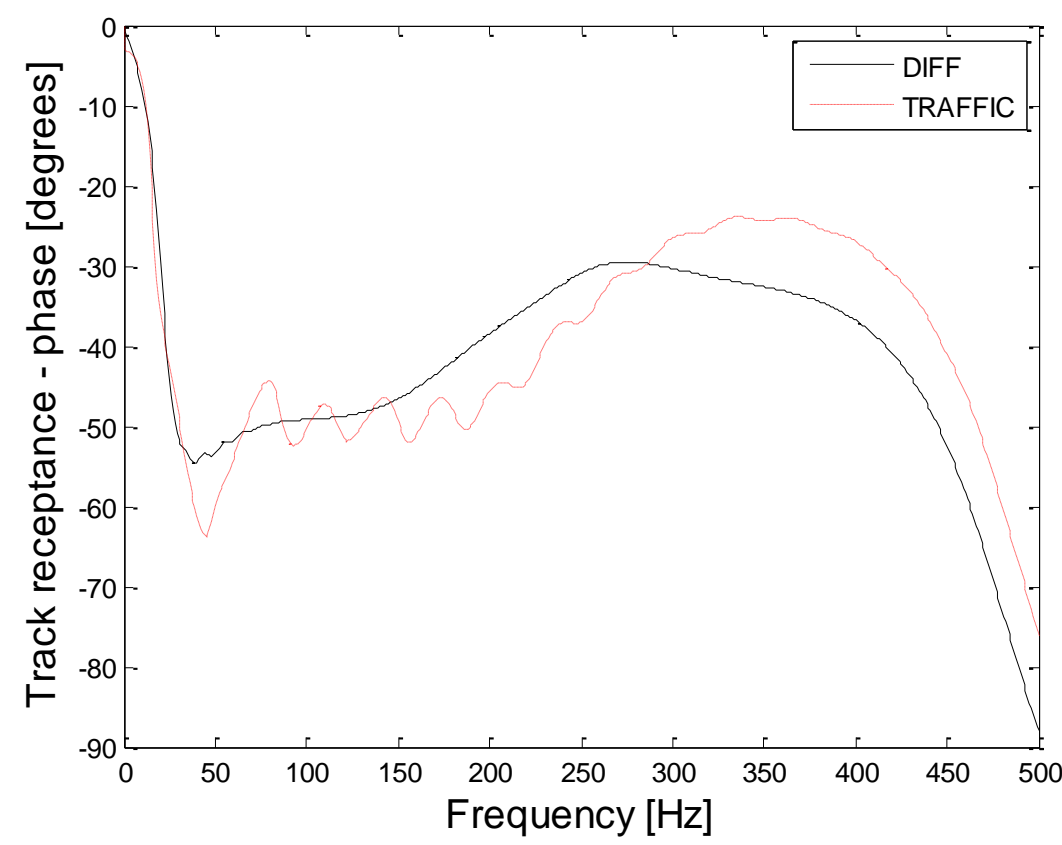

(b)

Figure 5. (a) Magnitude and (b) phase of track receptance (symmetric load applied on two rails) for the Lincent site. Comparison between TRAFFIC and tuned model in DIFF

Postprint submitted to Journal of Sound and Vibration

Published version: J.C.O. Nielsen, S. François, and G. Lombaert,. A hybrid model for prediction of ground-borne vibration due to discrete wheel/rail irregularities. Journal of Sound and Vibration, 345:103-120, 2015. http://dx.doi.org/10.1016/j.jsv.2015.01.021 
Postprint submitted to Journal of Sound and Vibration

Published version: J.C.O. Nielsen, S. François, and G. Lombaert,. A hybrid model for prediction of ground-borne vibration due to discrete wheel/rail irregularities. Journal of Sound and Vibration, 345:103-120, 2015. http://dx.doi.org/10.1016/j.jsv.2015.01.021 


\subsection{Hybrid model}

For load cases where non-linear wheel-rail contact conditions or variations in track support stiffness (parametric excitation) along the track model need to be considered, a solution approach involving an integration of analyses in DIFF and TRAFFIC is necessary. In this case, the transient vehicle-track interaction problem is solved in the time domain using DIFF and the Fourier transform of the calculated wheel-rail contact force is used as input to the TRAFFIC model where the ground vibration problem is solved in the frequency-wavenumber domain.

The procedure for the integration of DIFF and TRAFFIC used in the present application can be summarised as:

1. Use DIFF to calculate the transient wheel-rail contact force due to a discrete wheel/rail irregularity. For a wheel flat, consider a total time period of $0.5 \mathrm{~s}$ of the contact force time history including the response before and after the impact.

2. Subtract the static wheel load to obtain the dynamic wheel-rail contact force.

3. Assume symmetric load conditions and multiply the dynamic wheel-rail contact force with a factor 2 to obtain the dynamic axle load. Note that the track models in DIFF and TRAFFIC contain one and two rails, respectively. Switch sign of axle load from DIFF to account for different orientations of coordinate systems in DIFF and TRAFFIC.

4. Apply a Tukey window on the time history of the dynamic axle load to avoid spectral leakage of the signal in the subsequent frequency analysis.

5. Pad the time history of the dynamic axle loads with zeros to obtain a total time history of $1 \mathrm{~s}$ corresponding to a frequency resolution of $1 \mathrm{~Hz}$ in the subsequent analysis in TRAFFIC. The frequency resolution $1 \mathrm{~Hz}$ is considered sufficient here.

6. Calculate the Fourier transform of the dynamic axle load and use this as input to TRAFFIC.

7. Use TRAFFIC to calculate the track and ground response, see Equation (11).

The procedure will be demonstrated in Section 4.

\section{Demonstration}

In this Section, the presented hybrid modelling approach will be demonstrated by investigating the influence of wheel flat size on wheel-rail impact force and free field vibration.

\subsection{Quasi-static response}

Postprint submitted to Journal of Sound and Vibration

Published version: J.C.O. Nielsen, S. François, and G. Lombaert,. A hybrid model for prediction of ground-borne vibration due to discrete wheel/rail irregularities. Journal of Sound and Vibration, 345:103-120, 2015. http://dx.doi.org/10.1016/j.jsv.2015.01.021 
As discussed above, contributions to railway induced ground vibration are generated by both the quasi-static and dynamic components of the vertical wheel-rail contact forces. The Lincent site is along a high speed line with high-speed trains and conventional passenger traffic. For this site, it has been shown that the quasi-static contribution to the free field response is low even in case of high speed traffic [5]. This will hold as long as the train speed is lower than the wave velocities in the track and the soil. In the following, the case of a freight train wheelset with a wheel flat is considered for demonstration of the hybrid model. To enable a comparison of vibration magnitudes for the two types of excitation (assuming there would be freight traffic at Lincent), Figure 6 presents the calculated time histories of the free field response (displacement and velocity) at $8 \mathrm{~m}$ and $16 \mathrm{~m}$ from track due to the quasistatic excitation by a freight train at train speed $100 \mathrm{~km} / \mathrm{h}$. In Figure $6(\mathrm{~b})$, it is observed that the maximum free field velocity at $8 \mathrm{~m}$ from the track is lower than $0.1 \mathrm{~mm} / \mathrm{s}$.

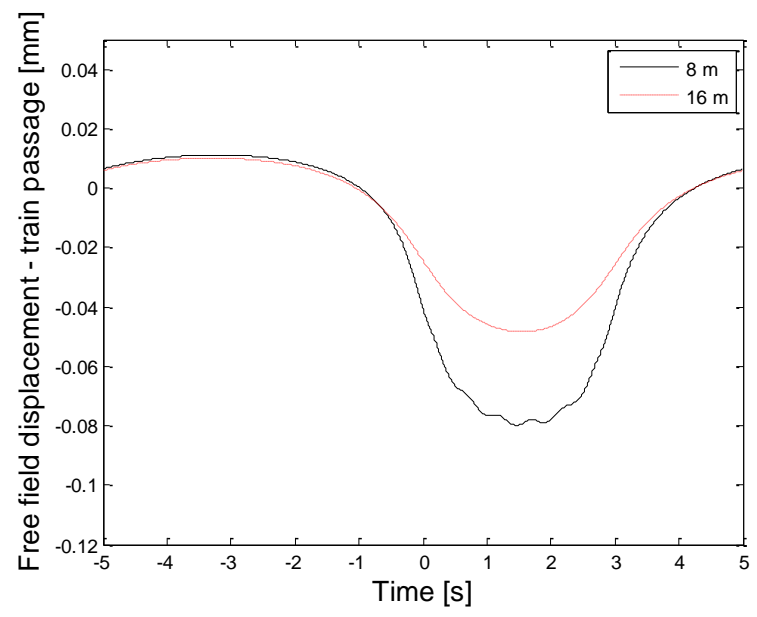

(a)

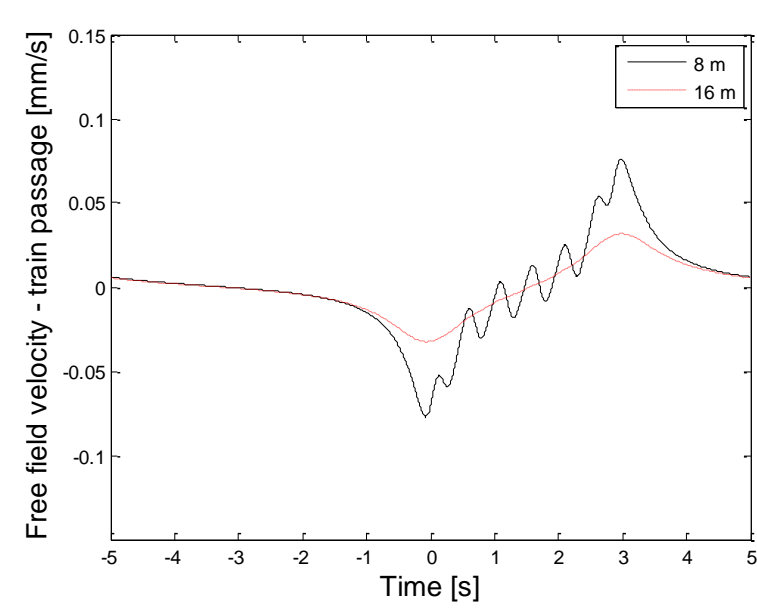

(b)

Figure 6. Time history of free field (a) displacement and (b) velocity at $8 \mathrm{~m}$ and $16 \mathrm{~m}$ from track. Vehicle model including six freight cars with Y25 bogies, axle load 22 tonnes and train speed $100 \mathrm{~km} / \mathrm{h}$

\subsection{Dynamic response}

The influence of a wheel flat on maximum wheel-rail contact force and free field vibration has been studied by the hybrid model (integration of the analyses in DIFF and TRAFFIC) described in Section 3.4. As discussed in Section 3.2, here the vehicle model can be assumed to be located at a fixed position along the track model in TRAFFIC. The vehicle model contains one wheelset of an Y25 bogie with axle load 22 tonnes, and it is assumed that the wheel flat strikes the rail only once. Soil conditions according to the Lincent test site are assumed, see Appendix. The investigated frequency range is $0-500 \mathrm{~Hz}$ with frequency step 1 
Hz. In order to focus on ground vibration generated by impact loading due to a wheel flat, no track irregularities are considered in the present calculations.

The influence of a wheel flat is modelled by a prescribed relative displacement of wheel and rail according to [11]. Both new and rounded wheel flats are considered. For a new flat with sharp corners (before rounding of the corners due to wear and plastic deformation), the length $l_{0}$ and depth $d$ of the flat are related by the chord theorem and it can be shown that $d \approx l_{0}^{2} / 8 R$ where $R$ is the wheel radius [11]. The wheel will pivot about the leading corner (edge) of the flat until the flat is horizontal and then it will pivot about the rear corner of the flat until it starts rolling again. For a rounded flat, the profile of each corner is assumed to be described by a quadratic function with a smooth transition to the centre part of the flat which is assumed to maintain its initial shape. Examples of prescribed wheel trajectories for two different initial flat lengths are shown in Figure 7. It is observed that the depth of the flat is assumed to be unaffected by the rounding of the corners.

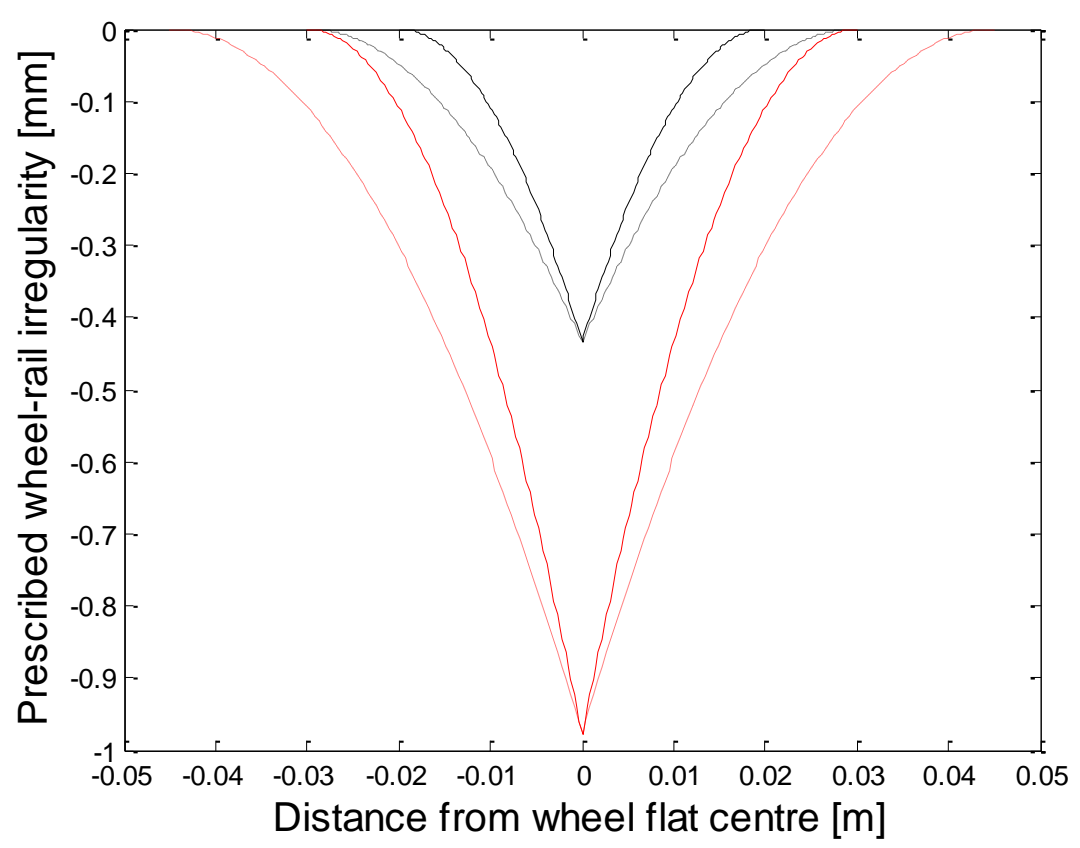

Figure 7. Prescribed wheel-rail irregularity due to wheel flats with different lengths and depths (wheel radius $0.46 \mathrm{~m}$ ): new flat with length $l_{0,1}=40 \mathrm{~mm}$ (black, solid line), rounded flat with length $1.5 l_{0,1}$ and same depth as new flat with length $l_{0,1}$ (black, dashed line), new flat with length $l_{0,2}=60 \mathrm{~mm}$ (red, solid line), rounded flat with length $1.5 l_{0,2}$ and same depth as new flat with length $l_{0,2}$ (red, dashed line)

Different steps of the numerical procedure for the calculation of free field velocity due to a rounded flat (with length $l=1.5 l_{0}$, where $l_{0}=60 \mathrm{~mm}$ and depth $d=0.98 \mathrm{~mm}$ ) are illustrated in Figures 8 and 9. The ground vibration is calculated using Equation (11). Two different axle loads are considered. After application of a Tukey window, the part of the time history of the contact force containing the impact (from DIFF) is shown in Figures 8(a) and 9(a). The Postprint submitted to Journal of Sound and Vibration

Published version: J.C.O. Nielsen, S. François, and G. Lombaert,. A hybrid model for prediction of ground-borne vibration due to discrete wheel/rail irregularities. Journal of Sound and Vibration, 345:103-120, 2015. http://dx.doi.org/10.1016/j.jsv.2015.01.021 
Fourier transform (frequency resolution $1 \mathrm{~Hz}$ ) of the dynamic component of the contact force is calculated and plotted in Figures 8(b) and 9(b). The Fourier transform of the contact force is multiplied with the free field mobility (see Figure 4) to obtain the frequency content of the free field velocity at $8 \mathrm{~m}$ and $16 \mathrm{~m}$ from track, see Figures $8(\mathrm{c}, \mathrm{e})$ and $9(\mathrm{c}, \mathrm{e})$. Finally, the time history of the free field velocity is calculated by an inverse Fourier transform from the frequency domain, see Figures $8(\mathrm{~d}, \mathrm{f})$ and $9(\mathrm{~d}, \mathrm{f})$. Note that the same methodology can be used to study the influence of parametric excitation on ground vibration.

The influence of axle load and vehicle speed on free field velocity generated by a wheel flat is observed in Figures 8 and 9. For the axle load of 10 tonnes, there is loss of contact between wheel and rail at both vehicle speeds $30 \mathrm{~km} / \mathrm{h}$ and $100 \mathrm{~km} / \mathrm{h}$. At the lower speed, the flight time is longer and the rear corner of the wheel flat strikes the rail with an impact load that is higher in magnitude and has significant frequency contributions below $100 \mathrm{~Hz}$, see Figures 8(a-b). According to Figure 4, the free field mobility at Lincent is high in this frequency range. Thus, the studied wheel flat results in high vibration levels especially at the lower speed, see Figure 8(d). A strong attenuation of the high frequency components of ground vibration with increasing distance is observed by comparing Figures 8(c) and 8(e). At speed $30 \mathrm{~km} / \mathrm{h}$, the maximum vibration at $8 \mathrm{~m}$ from track is in the order of $6 \mathrm{~mm} / \mathrm{s}$ which is considerably higher than the vibration generated by the quasi-static load, cf. Figure 6(b).

For the axle load of 22 tonnes, the magnitude of the wheel-rail contact force is higher but the dynamic component of the impact load is similar as for the lower axle load, see Figures $9(a, b)$. The higher vehicle speed leads to loss of contact between wheel and rail but not to a higher impact load. In particular, for the lower speed, the frequency content of the dynamic wheel-rail contact force is more significant at frequencies below $100 \mathrm{~Hz}$.

Postprint submitted to Journal of Sound and Vibration

Published version: J.C.O. Nielsen, S. François, and G. Lombaert,. A hybrid model for prediction of ground-borne vibration due to discrete wheel/rail irregularities. Journal of Sound and Vibration, 345:103-120, 2015. http://dx.doi.org/10.1016/j.jsv.2015.01.021 


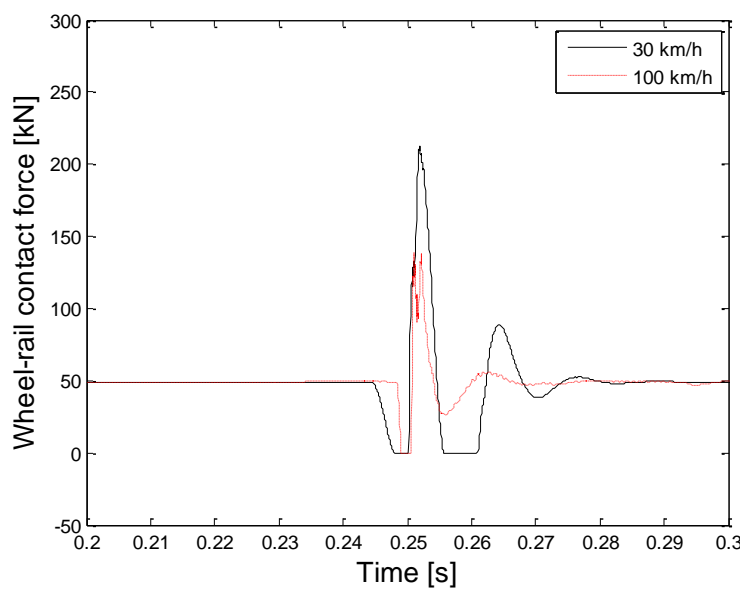

(a)

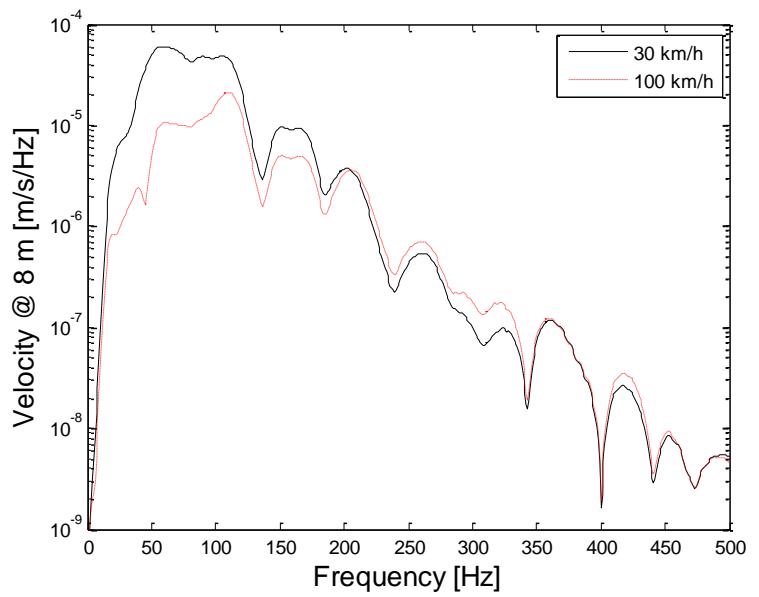

(c)

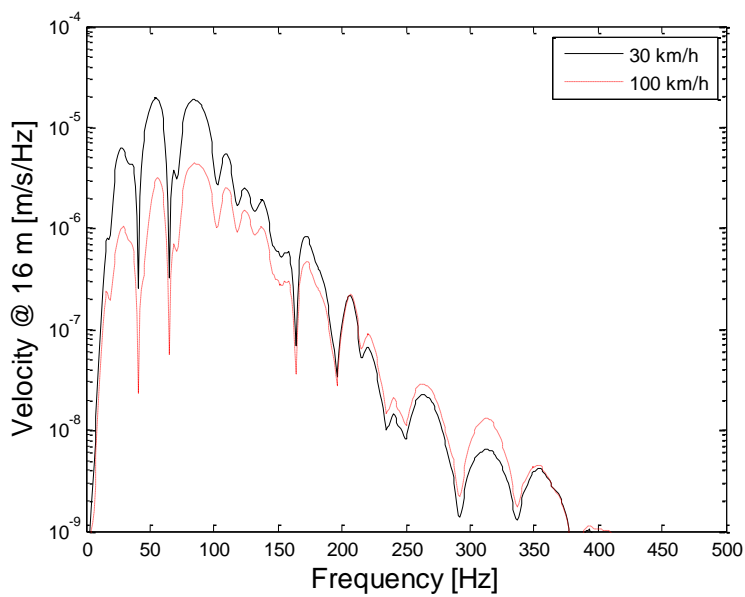

(e)

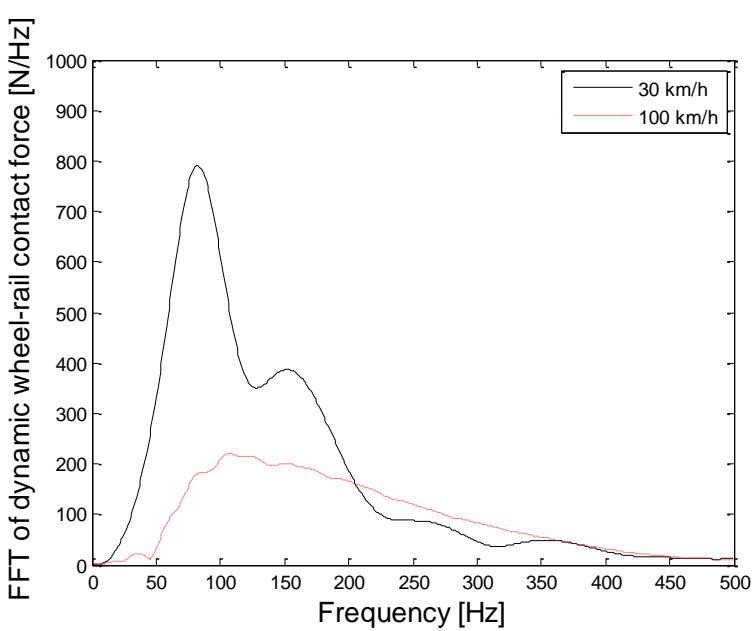

(b)

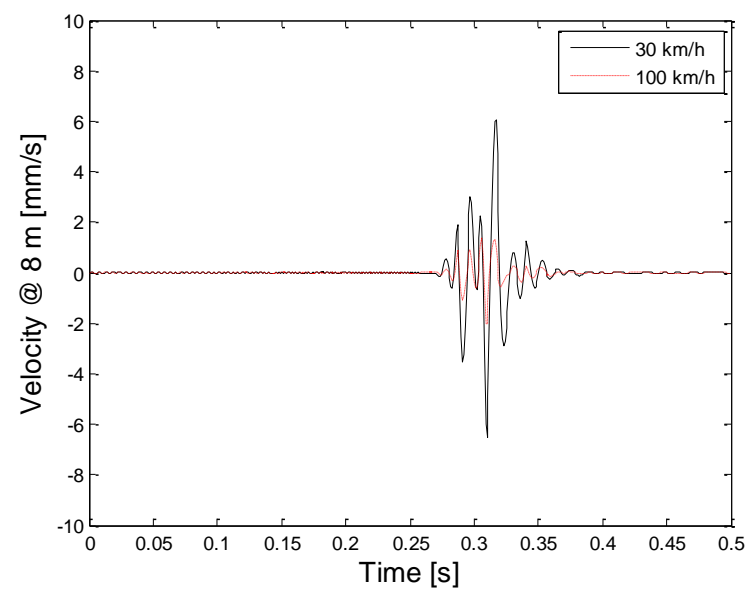

(d)

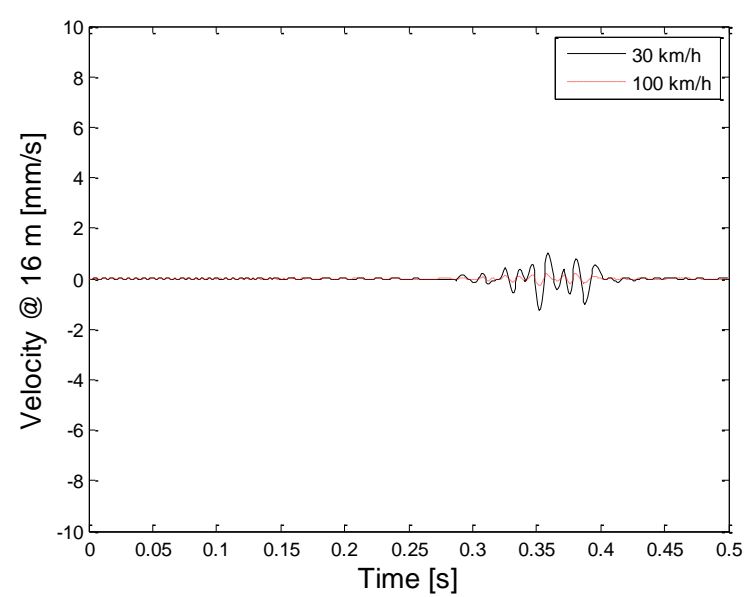

(f)

Figure 8. Calculation of free field velocity due to passage of a single wheelset of a Y25 bogie with axle load 10 tonnes, rounded wheel flat with length $l=1.5 l_{0}$ where $l_{0}=60 \mathrm{~mm}$ and depth $0.98 \mathrm{~mm}$ (see Figure 7): (a) time history of vertical wheel-rail contact force after application of Tukey window, Postprint submitted to Journal of Sound and Vibration

Published version: J.C.O. Nielsen, S. François, and G. Lombaert,. A hybrid model for prediction of ground-borne vibration due to discrete wheel/rail irregularities. Journal of Sound and Vibration, 345:103-120, 2015. http://dx.doi.org/10.1016/j.jsv.2015.01.021 
(b) Fourier transform of dynamic component of contact force, (c) frequency content of free field velocity at $8 \mathrm{~m}$ from track, (d) time history of free field velocity at $8 \mathrm{~m}$ from track, (e) frequency content of free field velocity at $16 \mathrm{~m}$ from track, (f) time history of free field velocity at $16 \mathrm{~m}$ from track

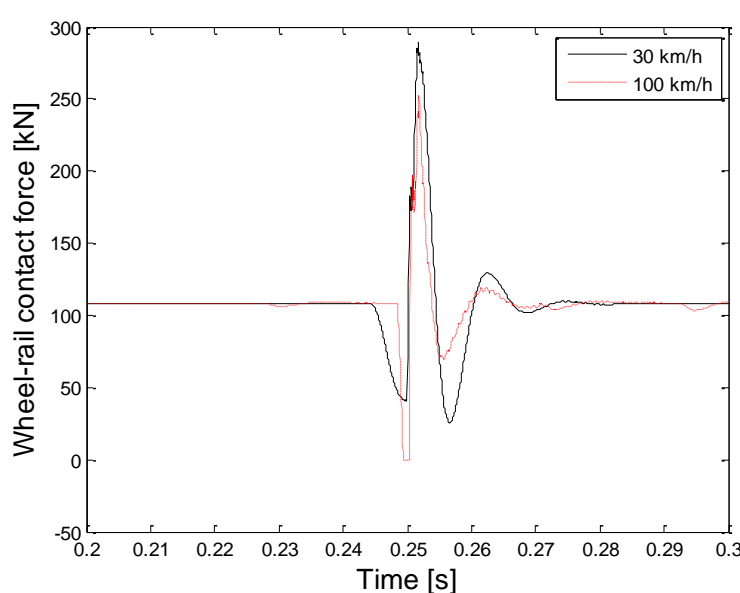

(a)

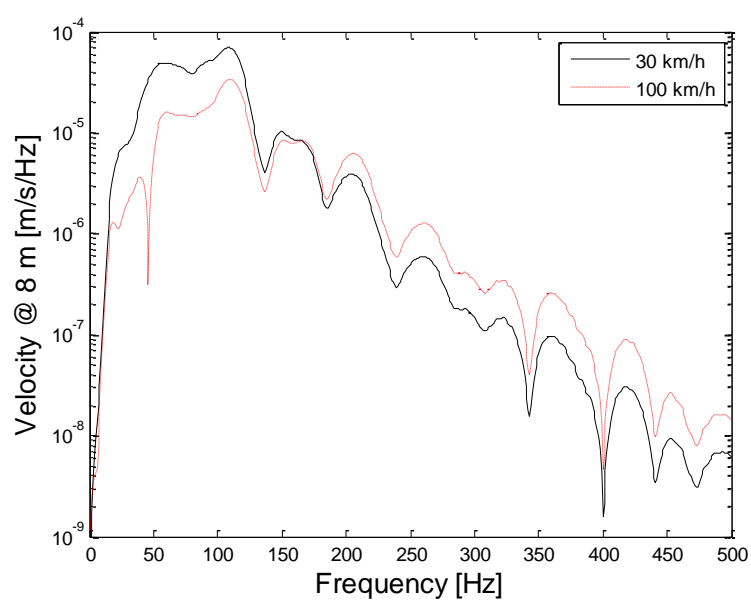

(c)

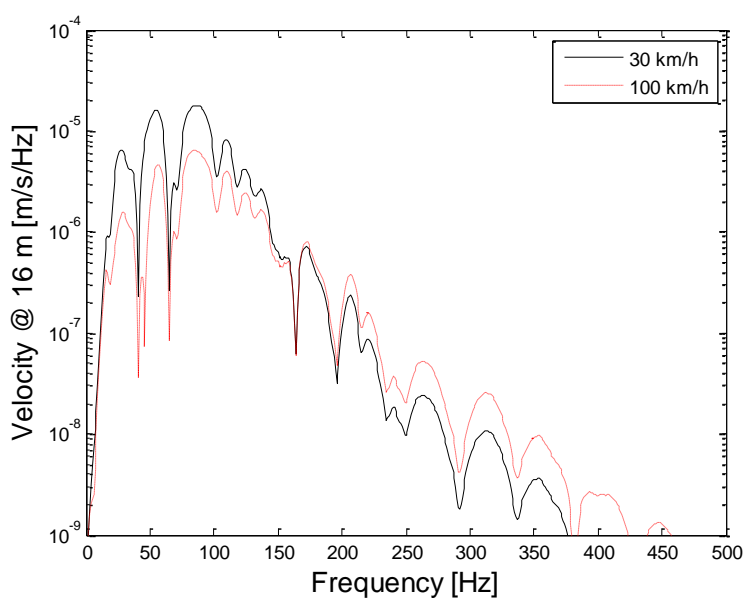

(e)

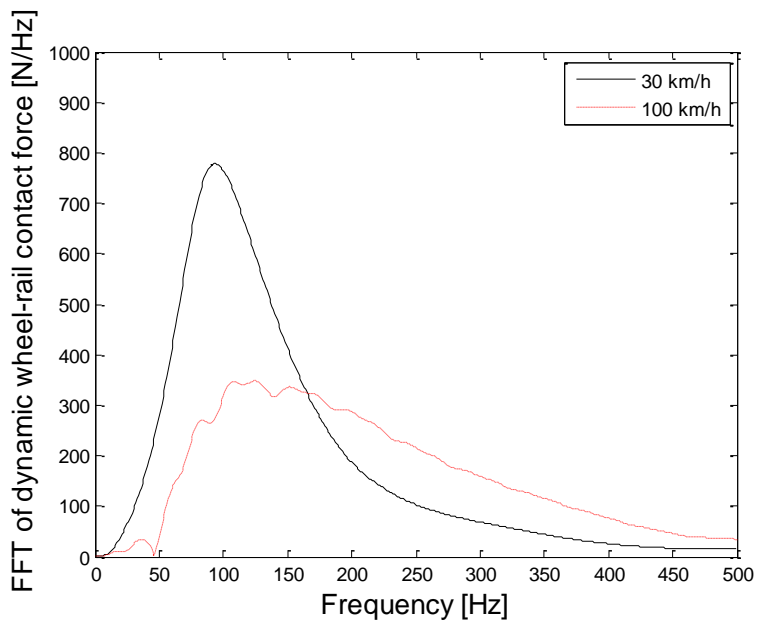

(b)

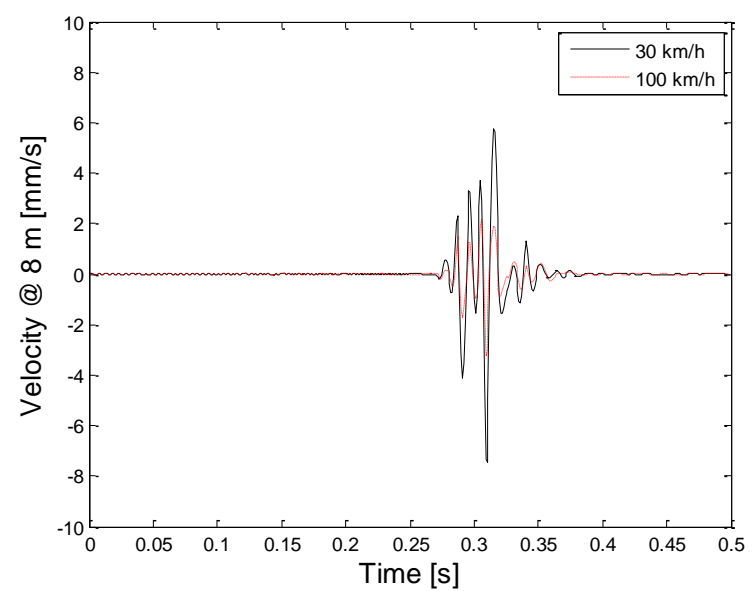

(d)

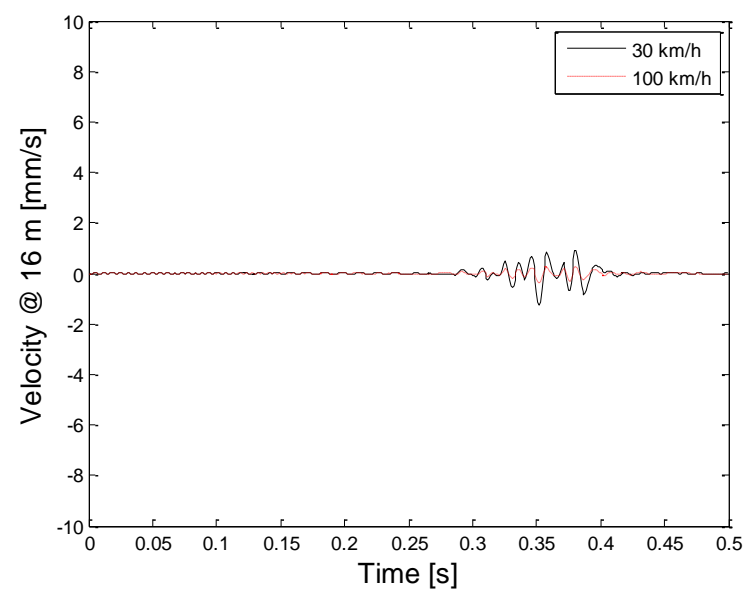

(f)

Postprint submitted to Journal of Sound and Vibration

Published version: J.C.O. Nielsen, S. François, and G. Lombaert,. A hybrid model for prediction of ground-borne vibration due to discrete wheel/rail irregularities. Journal of Sound and Vibration, 345:103-120, 2015. http://dx.doi.org/10.1016/j.jsv.2015.01.021 
Figure 9. Calculation of free field velocity due to passage of a single wheelset of a Y25 bogie with axle load 22 tonnes, rounded wheel flat with length $l=1.5 l_{0}$ where $l_{0}=60 \mathrm{~mm}$ and depth $0.98 \mathrm{~mm}$ (see Figure 7): (a) time history of vertical wheel-rail contact force after application of Tukey window, (b) Fourier transform of dynamic component of contact force, (c) frequency content of free field velocity at $8 \mathrm{~m}$ from track, (d) time history of free field velocity at $8 \mathrm{~m}$ from track, (e) frequency content of free field velocity at $16 \mathrm{~m}$ from track, (f) time history of free field velocity at $16 \mathrm{~m}$ from track

\subsection{Influence of wheel flat size}

For new and rounded flats and for the track and soil conditions given at Lincent, the influence of wheel flat length and vehicle speed on maximum wheel-rail contact force is illustrated in Figure 10 (axle load 22 tonnes). As expected, it is observed that the maximum contact force increases with increasing wheel flat length (and depth). For the new flat with length $l_{0}$, there is a local maximum in impact load at vehicle speed around $30 \mathrm{~km} / \mathrm{h}$, see Figure 10(a). The corresponding maximum for the rounded flat with length $1.5 l_{0}$ is at vehicle speed $45 \mathrm{~km} / \mathrm{h}$. The presence of a local maximum in contact force in this vehicle speed range is in agreement with field measurements at other sites, see e.g. [33].

Loss of wheel-rail contact is observed for most combinations of wheel flat length and vehicle speed, motivating the use of the hybrid model. However, for the shortest flat studied, maintained contact is predicted at low speeds (up to $55 \mathrm{~km} / \mathrm{h}$ for the new flat and up to $85 \mathrm{~km} / \mathrm{h}$ for the rounded flat). For conditions with maintained wheel-rail contact, the response of the coupled vehicle-track system can be expressed as, see [1],

$$
\hat{F}_{\mathrm{a}}(\omega)=-\frac{\hat{u}_{\mathrm{w} / \mathrm{r}}(\omega)}{\hat{\mathbf{H}}^{\mathrm{t}}(\omega)+\hat{\mathbf{H}}^{\mathrm{v}}(\omega)}
$$

where $\hat{u}_{\mathrm{w} / \mathrm{r}}$ is the wheel/rail irregularity representation in the frequency domain, while $\hat{\mathbf{H}}^{\mathrm{t}}(\omega)$ and $\hat{\mathbf{H}}^{\mathrm{v}}(\omega)$ are the track and vehicle receptance vectors, respectively. This equation shows that the vehicle-track interaction is determined by the receptance of the coupled system. At the so-called P2 resonance frequency, the inertia of the mass moving on the track $\left(\hat{\mathbf{H}}^{v}\right)$ is balanced by the spring stiffness of the track $\left(\hat{\mathbf{H}}^{\mathrm{t}}\right)$ and the receptance of the coupled system has a minimum value [1].

For the studied DIFF model of the coupled system at Lincent, the predicted P2 resonance is $175 \mathrm{~Hz}$, see Figure 11, corresponding to a natural period of $T=5.7 \mathrm{~ms}$. The duration of the irregularity input induced by a wheel flat with length $l_{0}$ is $t_{\mathrm{d}}=l_{0} / v$. For $l_{0}=40 \mathrm{~mm}$ and the observed maximum in contact force at $30 \mathrm{~km} / \mathrm{h}$, the ratio $t_{\mathrm{d}} / T=0.84$. This may be compared with the ratio of dynamic to static response for a SDOF system subjected to a triangular pulse loading which reaches its maximum at a ratio $t_{\mathrm{d}} / T$ of about 1 [34]. For another set of track conditions, it has been predicted by numerical simulations that the local maximum in contact force is shifting to increasing vehicle speed with increasing wheel flat length (maintained

Postprint submitted to Journal of Sound and Vibration

Published version: J.C.O. Nielsen, S. François, and G. Lombaert,. A hybrid model for prediction of ground-borne vibration due to discrete wheel/rail irregularities. Journal of Sound and Vibration, 345:103-120, 2015. http://dx.doi.org/10.1016/j.jsv.2015.01.021 
wheel-rail contact) [35]. This confirms that Equation (15) can be applied to explain the local maximum in contact force at low vehicle speeds for vehicles with wheel flats.

The influence of vehicle speed and length of a new wheel flat on free field velocity at $8 \mathrm{~m}$ and $16 \mathrm{~m}$ from track is illustrated in Figure 12 (new flat) and Figure 13 (rounded flat). As expected, the free field velocity increases with increasing wheel flat size. For a given wheel flat, the free field velocity is reduced by increasing the vehicle speed since the frequency content of the dynamic wheel-rail contact force is shifted to higher frequencies where the free field mobility is lower. Note the significant reduction in maximum free field velocity with increasing distance from the track.

For comparison, RMS values of free field velocity have previously been evaluated for different standard spectra of longitudinal level (vertical track irregularity), see [13]. The RMS-values were evaluated over the frequency interval $1-200 \mathrm{~Hz}$. Assuming the irregularity spectrum according to ORE B176 (high) [36], vehicle speed $100 \mathrm{~km} / \mathrm{h}$ and soil conditions according to Lincent, the calculated RMS-value at 8 and $16 \mathrm{~m}$ were 0.42 and $0.18 \mathrm{~mm} / \mathrm{s}$, respectively. Thus, it is confirmed that impact excitation due to wheel flats is a severe source of ground vibration.

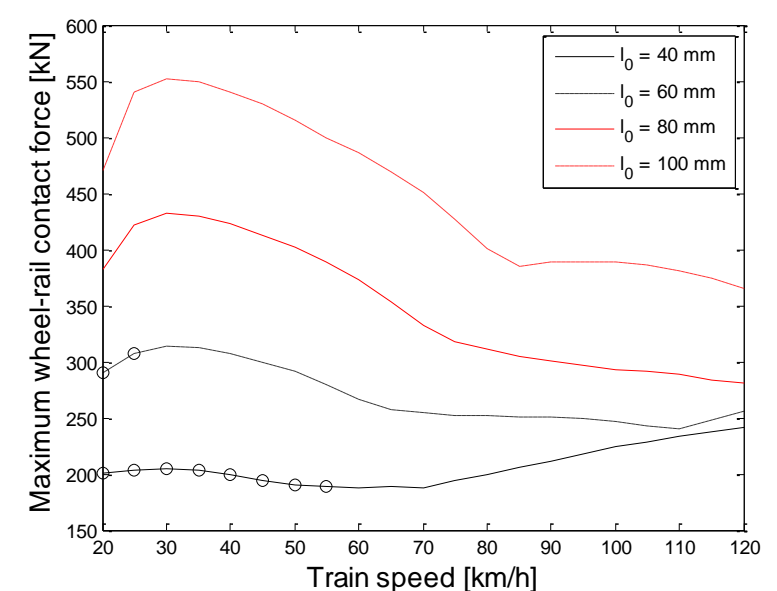

(a)

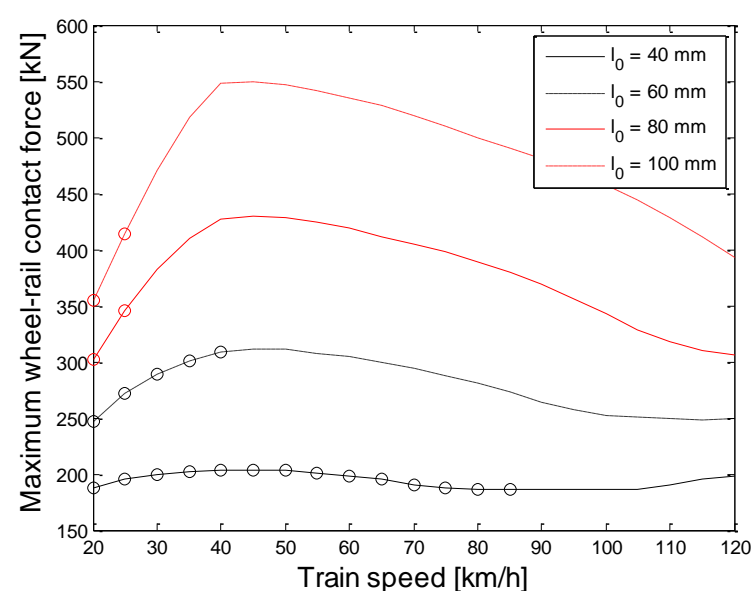

(b)

Figure 10. Influence of train speed and length of wheel flat on maximum wheel-rail impact load (a) new wheel flat with length $l_{0}$ and (b) rounded wheel flat with length $1.5 l_{0}$. Vehicle model including one wheelset of an Y25 bogie, axle load 22 tonnes and track conditions according to Lincent. Circles indicate that loss of wheel-rail contact has not occurred before impact

Postprint submitted to Journal of Sound and Vibration

Published version: J.C.O. Nielsen, S. François, and G. Lombaert,. A hybrid model for prediction of ground-borne vibration due to discrete wheel/rail irregularities. Journal of Sound and Vibration, 345:103-120, 2015. http://dx.doi.org/10.1016/j.jsv.2015.01.021 


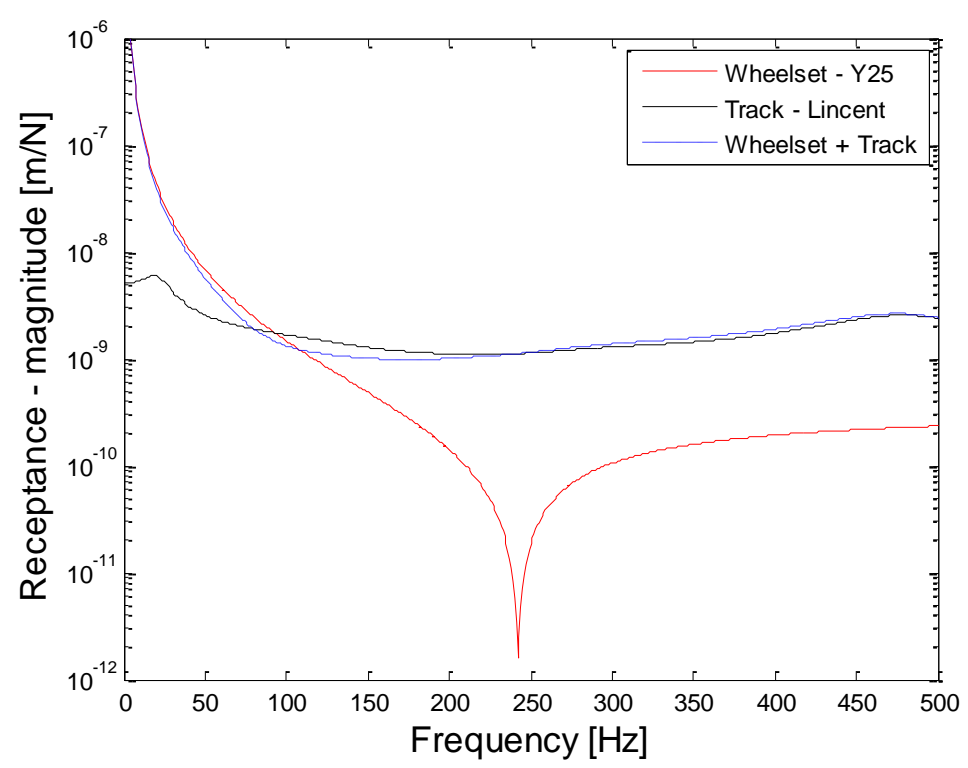

Figure 11. Magnitude of receptance for wheelset, track (DIFF) and coupled system. Local minimum of receptance for coupled system at $175 \mathrm{~Hz}$

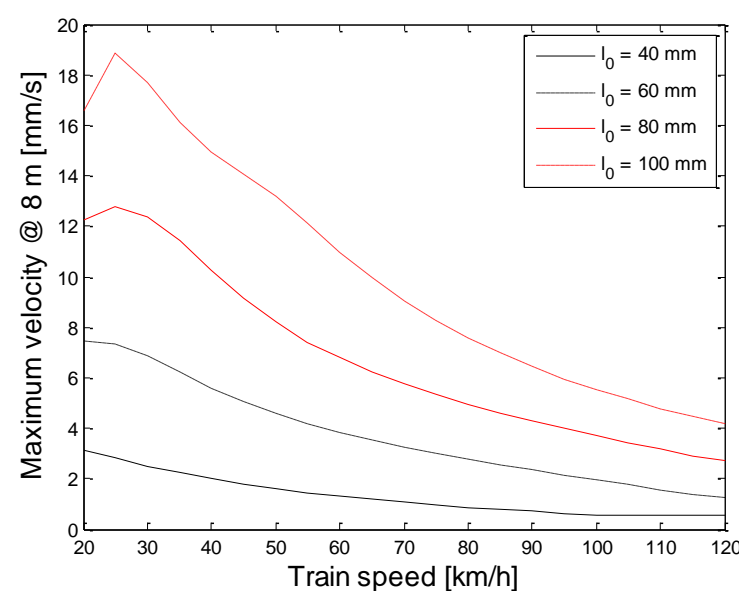

(a)

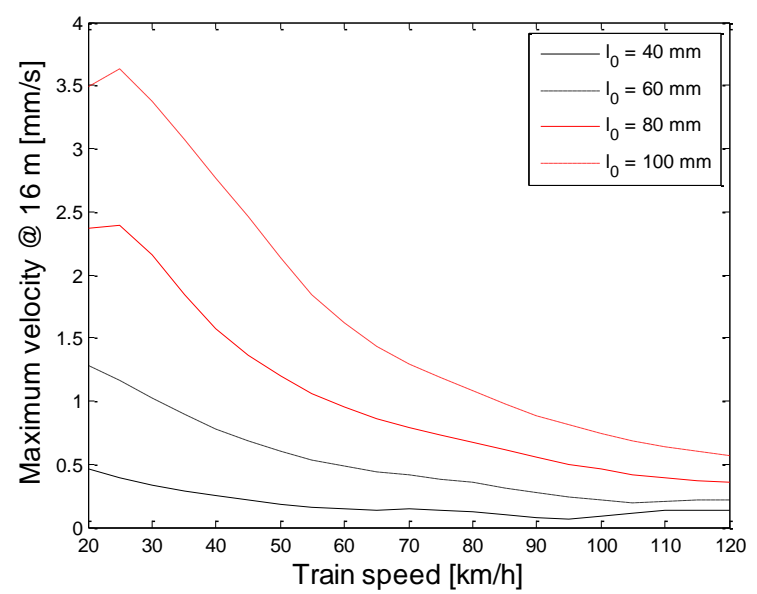

(b)

Figure 12. Influence of train speed and length of new wheel flat with length $l_{0}$ on maximum free field velocity at (a) $8 \mathrm{~m}$ and (b) $16 \mathrm{~m}$. Vehicle model including one wheelset of an Y25 bogie, axle load 22 tonnes and track conditions according to Lincent

Postprint submitted to Journal of Sound and Vibration

Published version: J.C.O. Nielsen, S. François, and G. Lombaert,. A hybrid model for prediction of ground-borne vibration due to discrete wheel/rail irregularities. Journal of Sound and Vibration, 345:103-120, 2015. http://dx.doi.org/10.1016/j.jsv.2015.01.021 


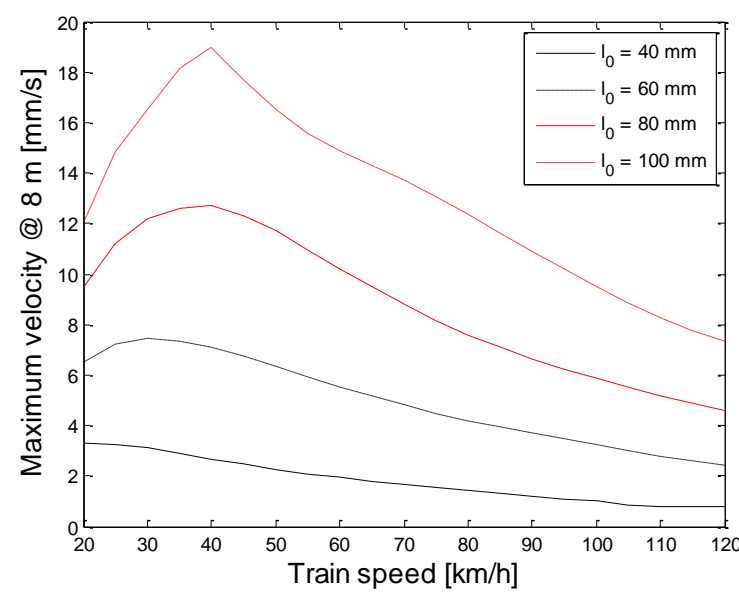

(a)

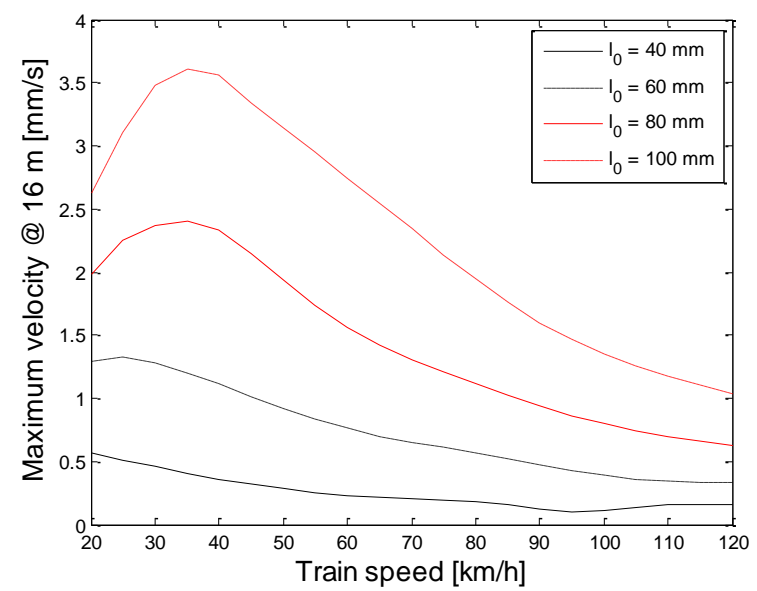

(b)

Figure 13. Influence of train speed and length of rounded wheel flat with length $1.5 l_{0}$ on maximum free field velocity at (a) $8 \mathrm{~m}$ and (b) $16 \mathrm{~m}$. Vehicle model including one wheelset of an Y25 bogie, axle load 22 tonnes and track conditions according to Lincent

\section{Conclusions}

The dynamic component of the vertical wheel-rail contact force generated by wheel and rail irregularities is an important source of ground vibration and ground-borne noise. Wheel flats and other discrete wheel/rail irregularities often lead to loss of wheel-rail contact followed by a high magnitude impact load. However, most computationally efficient models for the prediction of ground vibration in layered soils are linear and assume continuous (maintained) wheel-rail contact conditions. Also the influence of parametric excitation due to sleeper periodicity is neglected. To study the influence of parametric and impact excitations, a solution in the time domain is required. In the present study, a hybrid modelling approach has been presented which combines the features of two models of dynamic vehicle-track interaction. The influence of discrete wheel/rail irregularities on the time history of impact excitation is determined by the time domain model. The Fourier transform of the impact excitation is then used as input to a frequency-wavenumber domain model to predict the ground vibration of a layered soil. Note that the presented methodology is general and can be used to study other forms of transient excitation such as parametric excitation due to sleeper periodicity and impact excitation due to different types of track irregularity.

For an accurate combination of the two models, it is required that the vehicle and track receptances at the wheel-rail contacts of the two models are similar. Tuning of the track receptances also ensures that the force applied to the track introduces the same amount of energy in both track models. The tuning is a challenge in particular for the low-frequency track receptance due to the significant differences between the two models in the modelling of ballast and ground. To meet this challenge, the input data of a five-parameter discretised soil

Postprint submitted to Journal of Sound and Vibration

Published version: J.C.O. Nielsen, S. François, and G. Lombaert,. A hybrid model for prediction of ground-borne vibration due to discrete wheel/rail irregularities. Journal of Sound and Vibration, 345:103-120, 2015. http://dx.doi.org/10.1016/j.jsv.2015.01.021 
model in the time domain model are determined by minimising the quadratic error function based on the sum of differences between the receptances calculated for the two models.

For new and rounded wheel flats, the influence of wheel flat length and vehicle speed on maximum wheel-rail contact force has been studied. As expected, it was observed that the maximum contact force increases with increasing wheel flat length (and depth). However, the influence of vehicle speed was not as clear. For the rounded flat, a local maximum in impact load at vehicle speed around $45 \mathrm{~km} / \mathrm{h}$ was identified. Also as expected, the free field velocity increases with increasing wheel flat size. For a given wheel flat, above the speed leading to the maximum in impact load, it was shown that the free field velocity is reduced by increasing vehicle speed since the frequency content of the dynamic wheel-rail contact force is shifted to higher frequencies which may be less significant for ground vibration. Further, it was found that the magnitudes of ground vibration generated by the studied wheel flats were considerably higher than those induced by a common level of vertical track irregularity (longitudinal level).

The unsprung mass and wheel out-of-roundness are key vehicle related parameters determining the generation of ground-borne vibration. Means for reducing the unsprung mass are discussed in [37] including alternative designs for the wheelset and the suspension of the mechanical drive system. To reduce ground vibration, several measures on rolling stock need to be implemented: (1) Stations for monitoring of wheel tread conditions allowing for condition based wheel maintenance; (2) improved brake system design, wheel slide protection and wheel material quality to avoid wheel flats and other discrete wheel tread defects; (3) reduction of unsprung mass, in particular for locomotives, by application of suspended drive design concepts; and (4) radial steering of wheelsets to reduce wear and wheel polygonalisation in small radius curves [37].

Postprint submitted to Journal of Sound and Vibration

Published version: J.C.O. Nielsen, S. François, and G. Lombaert,. A hybrid model for prediction of ground-borne vibration due to discrete wheel/rail irregularities. Journal of Sound and Vibration, 345:103-120, 2015. http://dx.doi.org/10.1016/j.jsv.2015.01.021 


\section{Acknowledgements}

The current study was carried out in the research project RIVAS (Railway Induced Vibration Abatement Solutions) supported by the European Union Seventh Framework Programme under grant agreement no 265754.

\section{Appendix: Track model input data}

The input data for the track superstructure models in TRAFFIC and DIFF are listed in Table A1.

Besides the fact that a half-space model is not available in DIFF, there are a few other features that distinguish the two models: In TRAFFIC the rails are modelled as Euler-Bernoulli beams, whereas in DIFF the rails are described by Rayleigh-Timoshenko beam theory. In TRAFFIC both rails are considered but in DIFF the vehicle/track vibration is assumed to be symmetric with reference to a centre line along the track and thus a model of half the track is sufficient. For DIFF, this means the input data for sleeper and ballast is per half sleeper. The continuous rail support in TRAFFIC versus the discrete support in DIFF has implications on the input data in Table A1. The damping is taken as viscous in both models. The ballast body interacting with each sleeper is described by a rectangular parallelepiped with (sleeper) length $2.6 \mathrm{~m}$, (sleeper) width 0.25 and depth $0.3 \mathrm{~m}$. The properties of the ballast were determined based on the assumption that $80 \%$ of each sleeper is in contact with the ballast (the influence of the remaining $20 \%$ is neglected in the calculation of ballast stiffness, damping and mass). The viscous ballast damping in both models was determined by assuming structural damping with loss factor 0.04 and calculating an equivalent viscous damping at $20 \mathrm{~Hz}$.

Input data for the layered soil model in TRAFFIC is listed in Table A2.

Postprint submitted to Journal of Sound and Vibration

Published version: J.C.O. Nielsen, S. François, and G. Lombaert,. A hybrid model for prediction of ground-borne vibration due to discrete wheel/rail irregularities. Journal of Sound and Vibration, 345:103-120, 2015. http://dx.doi.org/10.1016/j.jsv.2015.01.021 
Table A1. Input data for track superstructure (including ballast) used in TRAFFIC and DIFF

\begin{tabular}{|c|c|c|c|}
\hline & & TRAFFIC & DIFF \\
\hline \multirow[t]{5}{*}{ Rail (60E1) } & Bending stiffness per rail & $6.4 \cdot 10^{6} \mathrm{Nm}^{2}$ & $6.4 \cdot 10^{6} \mathrm{Nm}^{2}$ \\
\hline & Shear stiffness per rail & - & $248 \cdot 10^{6} \mathrm{~N}$ \\
\hline & Mass per unit length per rail & $60 \mathrm{~kg} / \mathrm{m}$ & $60 \mathrm{~kg} / \mathrm{m}$ \\
\hline & Position of left rail & $-0.7175 \mathrm{~m}$ & - \\
\hline & Position of right rail & $0.7175 \mathrm{~m}$ & - \\
\hline \multirow[t]{2}{*}{ Rail pad } & Stiffness & $500 \cdot 10^{6}(\mathrm{~N} / \mathrm{m}) / \mathrm{m}$ & $300 \cdot 10^{6} \mathrm{~N} / \mathrm{m}$ \\
\hline & Viscous damping & $25 \cdot 10^{3}(\mathrm{Ns} / \mathrm{m}) / \mathrm{m}$ & $15 \cdot 10^{3} \mathrm{Ns} / \mathrm{m}$ \\
\hline \multirow[t]{4}{*}{ Sleeper } & Sleeper distance & - & $0.6 \mathrm{~m}$ \\
\hline & Mass & $541.7 \mathrm{~kg} / \mathrm{m}$ & $162.5 \mathrm{~kg}$ \\
\hline & Mass moment of inertia & $306.9 \mathrm{kgm}$ & - \\
\hline & Length & $2.6 \mathrm{~m}$ & - \\
\hline \multirow[t]{3}{*}{ Ballast } & Mass & $520 \mathrm{~kg} / \mathrm{m}$ & $156 \mathrm{~kg}$ \\
\hline & Stiffness & $1.39 \cdot 10^{9}(\mathrm{~N} / \mathrm{m}) / \mathrm{m}$ & $416 \cdot 10^{6} \mathrm{~N} / \mathrm{m}$ \\
\hline & Viscous damping & $4.41 \cdot 10^{5}(\mathrm{Ns} / \mathrm{m}) / \mathrm{m}$ & $132 \cdot 10^{3} \mathrm{Ns} / \mathrm{m}$ \\
\hline
\end{tabular}

Table A2. Input data for layered soil model used in TRAFFIC corresponding to RIVAS reference test site Lincent

\begin{tabular}{|c|c|c|c|c|c|c|}
\hline Layer & $h$ & $C_{\mathrm{s}}$ & $C_{\mathrm{p}}$ & $\beta_{\mathrm{s}}$ & $\beta_{\mathrm{p}}$ & $\rho$ \\
\hline & {$[\mathrm{m}]$} & {$[\mathrm{m} / \mathrm{s}]$} & {$[\mathrm{m} / \mathrm{s}]$} & {$[-]$} & {$[-]$} & {$\left[\mathrm{kg} / \mathrm{m}^{3}\right]$} \\
\hline 1 & 1.4 & 128 & 286 & 0.044 & 0.044 & 1800 \\
\hline 2 & 2.7 & 176 & 286 & 0.038 & 0.038 & 1800 \\
\hline 3 & $\infty$ & 355 & 1667 & 0.037 & 0.037 & 1800 \\
\hline
\end{tabular}

Postprint submitted to Journal of Sound and Vibration

Published version: J.C.O. Nielsen, S. François, and G. Lombaert,. A hybrid model for prediction of ground-borne vibration due to discrete wheel/rail irregularities. Journal of Sound and Vibration, 345:103-120, 2015. http://dx.doi.org/10.1016/j.jsv.2015.01.021 


\section{References}

[1] G. Lombaert, G. Degrande, S. François, D.J. Thompson, Ground-borne vibration due to railway traffic: a review of excitation mechanisms, prediction methods and mitigation measures. In J.C.O. Nielsen et al. (Eds): Noise and Vibration Mitigation for Rail Transportation Systems, NNFM 126, pp 253-287, 2015 (Springer)

[2] D.J. Thompson, Railway noise and vibration: mechanisms, modelling and means of control, Elsevier, Amsterdam, The Netherlands, 2009

[3] X. Sheng, C.J.C. Jones, D.J. Thompson, A comparison of a theoretical model for quasistatically and dynamically induced environmental vibration from trains with measurements. Journal of Sound and Vibration 267(3) (2005) 621-635

[4] L. Auersch, Ground vibration due to railway traffic - The calculation of the effects of moving static loads and their experimental verification. Journal of Sound and Vibration 293 (2006) 599-610

[5] G. Lombaert, G. Degrande, P. Galvín, E. Bongini, F. Poisson, A comparison of predicted and measured ground vibrations due to high speed, passenger, and freight trains. In T. Maeda et al. (Eds): Noise and Vibration Mitigation for Rail Transportation Systems, NNFM 118, pp 231-238, 2012 (Springer)

[6] X. Sheng, C.J.C. Jones, D.J. Thompson, A theoretical model for ground vibration from trains generated by vertical track irregularities. Journal of Sound and Vibration 272(35) (2004) 937-965

[7] L. Auersch, The excitation of ground vibration by rail traffic: theory of vehicle-tracksoil interaction and measurements on high speed lines. Journal of Sound and Vibration 284(1-2) (2005) 103-132

[8] G. Lombaert, G. Degrande, J. Kogut, S. François, The experimental validation of a numerical model for the prediction of railway induced vibrations. Journal of Sound and Vibration 297(3-5) (2006) 512-535

[9] J.C.O. Nielsen, A. Igeland, Vertical dynamic interaction between train and track influence of wheel and track imperfections. Journal of Sound and Vibration 187(5) (1995) 825-839

[10] J.C.O. Nielsen, High-frequency vertical wheel-rail contact forces - validation of a prediction model by field testing. Wear 265 (2008) 1465-1471

[11] T.X. Wu, D.J. Thompson, A hybrid model for the noise generation due to railway wheel flats. Journal of Sound and Vibration 251(1) (2002) 115-139

[12] N. Triepaischajonsak, The influence of various excitation mechanisms on ground vibration from trains. Ph.D. thesis, University of Southampton, 2011

[13] J.C.O. Nielsen, Classification of track conditions with respect to vibration emission Part 1: Classification of track irregularities and numerical simulations, RIVAS (SCP0GA-2010-265754), Deliverable 2.1, June 2012, 74 pp

[14] J.C.O. Nielsen, Out-of-round railway wheels. In Wheel-rail interface handbook (edited by R Lewis and U Olofsson), 2009, Woodhead Publishing Ltd, Oxford, 842 pp

[15] J. Jergéus, Railway wheel flats - martensite formation, residual stresses and crack propagation, $\mathrm{PhD}$ thesis, Department of Solid Mechanics, Chalmers University of Technology, Sweden, 1998

[16] CEN, European Standard EN 15313, Railway applications - In-service wheelset operation requirements - In-service and off-vehicle wheelset maintenance, April 2010, $66 \mathrm{pp}$

Postprint submitted to Journal of Sound and Vibration

Published version: J.C.O. Nielsen, S. François, and G. Lombaert,. A hybrid model for prediction of ground-borne vibration due to discrete wheel/rail irregularities. Journal of Sound and Vibration, 345:103-120, 2015. http://dx.doi.org/10.1016/j.jsv.2015.01.021 
[17] D. Aubry, D. Clouteau, G. Bonnet, Modelling of wave propagation due to fixed or mobile dynamic sources. In N. Chouw, G. Schmid (Eds): Workshop Wave '94, Wave propagation and reduction of vibrations, pp 109-121, Ruhr Universität Bochum, Germany, December 1994

[18] S. François, M. Schevenels, G. Lombaert, P. Galvín, G. Degrande, A 2.5D coupled FE$\mathrm{BE}$ methodology for the dynamic interaction between longitudinally invariant structures and a layered halfspace. Computer Methods in Applied Mechanics and Engineering, 199(23-24) (2010) 1536-1548

[19] A.V. Metrikine, S.N. Verichev, J. Blauwendraad, Stability of a two-mass oscillator moving on a beam supported by a visco-elastic half-space. International Journal of Solids and Structures 42 (2005) 1187-1207

[20] X. Sheng, C.J.C. Jones, M. Petyt, Ground vibration generated by a harmonic load acting on a railway track. Journal of Sound and Vibration 225(1) (1999) 3-28

[21] C. Madshus, A.M. Kaynia, High-speed railway lines on soft ground: dynamic behaviour at critical train speed. Journal of Sound and Vibration 231(3) (2000) 689-701

[22] Y.B. Yang, H.H. Hung, A 2.5D finite-infinite element approach for modelling viscoelastic bodies subjected to moving loads. International Journal for Numerical Methods in Engineering 51 (2001) 1317-1336

[23] P.A. Costa, R. Calçada, A.S. Cardoso, A. Bodare, Influence of soil non-linearity on the dynamic response of high-speed railway tracks. Soil Dynamics and Earthquake Engineering 30(4) (2010) 221-235

[24] A. Karlström, A. Boström. An analytical model for train induced ground vibrations from railways. Journal of Sound and Vibration 292 (2006) 221-241

[25] J.A. Forrest, H.E.M. Hunt, A three-dimensional tunnel model for calculation of traininduced ground vibration. Journal of Sound and Vibration 294 (2006) 678-705

[26] K. Müller, H. Grundmann, S. Lenz, Nonlinear interaction between a moving vehicle and a plate elastically mounted on a tunnel. Journal of Sound and Vibration 310 (2008) 558-586

[27] X. Sheng, C.J.C. Jones, D.J. Thompson, Modelling ground vibrations from railways using wavenumber finite- and boundary-element methods. Proceedings of the Royal Society A - Mathematical, Physical and Engineering Sciences 461 (2005) 2043-2070

[28] T. Ekevid, N.-E.Wiberg, Wave propagation related to high-speed train. A scaled boundary FE-approach for unbounded domains. Computer Methods in Applied Mechanics and Engineering 191 (2002) 3947-3964

[29] T. Ekevid, H. Lane, N.-E. Wiberg, Adaptive solid wave propagation - influences of boundary conditions in high-speed train applications. Computer Methods in Applied Mechanics and Engineering 195 (2006) 236-250

[30] P. Galvín, A. Romero, J. Domínguez, Fully three-dimensional analysis of high-speed train-track-soil-structure dynamic interaction. Journal of Sound and Vibration 329 (2010) 5147-5163

[31] J. O'Brien, D.C. Rizos, A 3D FEM-BEM methodology for simulation of high speed train induced vibrations. Soil Dynamics and Earthquake Engineering 25 (2005) 289301

[32] C. Andersson, Modelling and simulation of train-track interaction including wear prediction, Department of Applied Mechanics, Chalmers University of Technology, Gothenburg, Sweden, PhD thesis, 2003

[33] A. Johansson, J.C.O. Nielsen, Out-of-round railway wheels - wheel-rail contact forces

Postprint submitted to Journal of Sound and Vibration

Published version: J.C.O. Nielsen, S. François, and G. Lombaert,. A hybrid model for prediction of ground-borne vibration due to discrete wheel/rail irregularities. Journal of Sound and Vibration, 345:103-120, 2015. http://dx.doi.org/10.1016/j.jsv.2015.01.021 
and track response derived from field tests and numerical simulations. Proc Instn Mech Engrs, Part F, Journal of Rail and Rapid Transit 217 (2003) 135-146

[34] A.K. Chopra, Dynamics of structures. Third Ed, 2007, Prentice Hall

[35] A. Pieringer, W. Kropp, J.C.O. Nielsen, The influence of contact modelling on simulated wheel/rail interaction due to wheel flats. Wear 314 (2014) 273-281

[36] ORE, Question B176: Bogies with steered or steering wheelsets, Report No 1 Specifications and preliminary studies, Volume 2: Specification for a bogie with improved curving characteristics, Utrecht, September 1989

[37] J.C.O. Nielsen, A. Mirza, S. Cervello, P. Huber, R. Müller, B. Nélain, P. Ruest, Reducing train-induced ground-borne vibration by vehicle design and maintenance. International Journal of Rail Transportation, 3 (2015) xxx-xxx. doi: $10.1080 / 23248378.2014 .994260$

Postprint submitted to Journal of Sound and Vibration

Published version: J.C.O. Nielsen, S. François, and G. Lombaert,. A hybrid model for prediction of ground-borne vibration due to discrete wheel/rail irregularities. Journal of Sound and Vibration, 345:103-120, 2015. http://dx.doi.org/10.1016/j.jsv.2015.01.021 